\title{
Trader see, trader do: How do (small) FX traders react to large counterparties' trades?
}

\author{
Lukas Menkhoff and Maik Schmeling* \\ Discussion Paper No.415 \\ March 2010 (revised) \\ ISSN 0949-9962
}

\begin{abstract}
:
We show that information about the counterparty of a trade affects the future trading decisions of individual traders. The effect is such that traders tend to reverse their order flow in line with the better-informed counterparties. Informed traders primarily incorporate their own private as well as publicly available information into prices, whereas uninformed traders mainly magnify the effect of the informed. This pattern of interaction among traders extends to different order types: traders treat their own and others' market orders as more informative than limit orders.
\end{abstract}

JEL Classification: G12, G15, D82, F31

Keywords: Foreign exchange microstructure, order flow, informed traders, counterparty identity

We would like to thank the participants of several seminars and the central bank workshop on the microstructure of financial markets in Hong Kong. In particular, we received helpful comments and suggestions from Stefan Frey, Thomas Gehrig, Anke Gerber, Carol Osler, Dagfinn Rime, Elvira Sojli, Wing Wah Tham, Erik Theissen and Giorgio Valente. We thank an anonymous referee for very constructive comments and gratefully acknowledge research assistance by Leila Gadijeva and financial support by the German Research Foundation (Deutsche Forschungsgemeinschaft DFG). An earlier draft of this research circulated under the title "Learning from post-trade identity disclosure in electronic trading."

Lukas Menkhoff, Maik Schmeling; Leibniz Universität Hannover, Department of Economics, Königsworther Platz 1, D-30167 Hannover, Germany

* corresponding: tel. ++49 (0)511 762 8213, fax. ++49 (0)511 762 4796, email. schmeling@gif.uni-hannover.de 


\section{Trader see, trader do: How do (small) FX traders react to large counterparties' trades?}

\section{Introduction}

Microstructure research has shown in several ways that foreign exchange markets are populated by heterogeneous participants. Participants have different institutional backgrounds (Sager and Taylor, 2006), they use different forms of analyses in making forecasts (Menkhoff and Taylor, 2007) and they differ in their knowledge of and access to price-relevant information. In this paper, we are interested in information heterogeneity across FX traders (e.g. Lyons, 1995; Peiers, 1997; Ito et al., 1998). Recently, a simple structural source of information heterogeneity in interbank trading has been uncovered, i.e. the size of a trading bank. Larger banks seem to know more than smaller banks and thus have a competitive advantage (e.g. Cheung and Chinn, 2001).

Information heterogeneity is a key to understanding the time-consuming price-discovery process: empirically, the incorporation of information into spot rates takes time and is not instantaneous (e.g. Lyons, 2001; Osler et al., 2006; Evans and Lyons, 2008; Ramadorai, 2008). Understanding how this process of price discovery takes place at the trader level can help to rationalize this finding. This is what we aim for in this paper.

So far, studies show that large traders seem to have an information advantage compared to the average market participant and thus have a greater price impact (Bjønnes et al., 2008; Menkhoff and Schmeling, 2008; Moore and Payne, 2009; Phylaktis and Chen, 2010). We build on this literature and push the analysis one step ahead and analyze the reaction of individual traders to the action of better-informed counterparties. Our data allow us to observe the trading decisions of all the traders in a market, so that we cannot only analyze the impact of large traders on other traders' actions but we can also investigate the interaction of large and 
small traders more generally. Building on this, we empirically show that traders tend to reverse their trading direction in line with their better-informed counterparties. This pattern is especially strong for small traders, persists over time and is thus consistent with the empirically observed time-consuming price-discovery process documented for FX markets (see e.g. Payne, 2003).

The analysis rests on an unusually detailed data set, i.e. the order book of an electronic foreign exchange market with complete order details and - more importantly - coded trader identities. The traders themselves do not know their counterparty's identity before a trade but get to know it once a trade has been completed for settlement purposes, so they can react to this private information when they conduct their next trade. This decision on the forthcoming trade of an individual trader is exactly what we are interested in. We employ the overall size of a trader (as opposed to the trade size) as a proxy for the likely degree of a trader's information and analyze in a panel approach whether it significantly affects traders' reactions to each other.

The main finding, that smaller traders tend to reverse their trading direction in line with the better informed, holds when we control for the full set of trading determinants as predicted by Goodhart (1988): trades do not only depend on the expected degree of information of the counterparty, but also depend positively on a trader's own former order flow (see Lyons, 2001) and former market-wide order flow (e.g. Evans and Lyons, 2002). These determinants represent trading motivation owing to private information and market-wide available information, respectively. Informed traders primarily incorporate their own private as well as publicly available information into prices, whereas the uninformed mainly magnify the effect of the informed. 
In further analyses, we show that our findings are not explained by order size but rather by the size of the counterparty and that counterparty information drives out the importance of public information as a determinant of individual trading decisions. Finally, the credibility of the above findings is underlined by distinguishing the analysis by order type. Consistent with economic intuition, we find that traders stick more strongly to their own market orders than to their limit orders, indicating that market orders contain relatively more private information. Complementing this pattern, traders react more strongly to the market orders of other traders relative to the limit orders of other traders.

Even though we are not aware of studies examining these interaction effects on the level of individual traders, there is related theoretical and empirical literature. Theoretical papers model trading among heterogeneously informed traders. Earlier models assume that traders possess heterogeneous private information and that they learn from observing the aggregate order flow such that information is revealed either quickly (Holden and Subrahmanyam, 1992) or slowly (e.g. Back, Cao and Willard, 2000). Colla and Mele (2010) enrich this setting by introducing an information linkage between individual traders. Linkage creates trader networks which lead to "correlated trading" among "close" traders. As a consequence one may think of three theoretically derived determinants of rational trade which substantiate Goodhart's (1988) observations: (i) private information including a history of own trades (Foster and Viswanathan, 1996), (ii) aggregate order flow and (iii) information gained from linkage with other traders. We will try to capture these three sources of information in our empirical approach below.

Among the empirical literature a first important strand follows Peiers (1997) in analyzing how - if at all - banks influence each other in their quoting behavior. These studies, including those of Dominguez (2003) and Chari (2007), consistently find dependencies in the 
quoting pattern but they do not confirm a "permanent" leadership of one or a few institutions. However, in all studies, the data refer to a small sample of (relatively homogeneous) large banks. A second strand analyzes individual currency traders, starting with Lyons (1995). These studies, including those of Bjønnes and Rime (2005), Osler et al. (2006) and Bjønnes et al. (2008), consistently confirm the relevance of asymmetric information - such as trading counterparties with different degree of information - to traders' decision-making. A last related strand shows that the identity of traders provides useful information to counterparties. In this respect, Foucault et al. (2007) demonstrate that closing pre-trade trader identifiers at the Paris Bourse in 2001 significantly decreased the information content of quotes, indicating that traders' identities provide relevant information. Porter and Weaver (1998) show for US stock markets that post-trade transparency also seems to be a valuable source of information that is worth being strategically delayed. Overall, these studies motivate the examination of the interaction of differently informed traders in real time.

The paper is organized around the following steps: Section 2 describes the data, Section 3 outlines the empirical approach and Section 4 provides and interprets the main results. Section 5 reports robustness results and Section 6 concludes.

\section{Data and preliminaries}

Market structure. The study covers a period in the year 2002 in the Russian interbank spot market for Russian roubles versus US dollars. At that time, the MICEX bourse in Moscow had introduced countrywide electronic trading in foreign exchange in which 722 traders participated. The trading platform has very similar characteristics to the main foreign exchange markets as it was designed in cooperation with Reuters. Participants see the best bid and ask prices with corresponding volumes. They also see information about the size of the 
last trade and cumulative trading volume of the market (cumulated over the current trading session). The usual price and time priorities apply in this market and there is no opening or closing auction. Like several other markets, including the Stock Exchange of Hong Kong (Ahn et al., 2001) and Island (Hasbrouck and Saar, 2009), the MICEX only permits limit orders. However, market orders can easily be constructed by placing limit orders at the best quote. All traders of this market, i.e. small and large traders, contribute to the provision of liquidity and there is no designated market maker.

As in many electronic FX markets (e.g. the EBS or REUTERS trading systems), trading is anonymous and identification is only revealed after completing a trade, i.e. there is posttrade but not pre-trade identity disclosure. Disclosure takes place via an e-mail messaging system similar to the Reuters FX dealing systems. Immediately after the completion of a trade, both traders obtain information about the counterparty's identity for settlement purposes.

Since the trading system we analyze is similar to other existing limit order markets, we believe that our findings are instructive for other markets with a similar structure, such as the main foreign exchange markets and many stock markets organized around a limit order book (Porter and Weaver, 1998, Parlour and Seppi, 2008). Moreover, the working of post-trade identity disclosure is also of interest for limit order markets in general as it captures an intermediate form between the more common market form with pre- and post-trade disclosure and the increasingly important market form with both pre- and post-trade anonymity.

The importance of the currency market analyzed here stems from the fact that it channels trading activity in Russia whereas earlier exchanges only operated in certain regions of the country and there was no country-wide trading on a single exchange. Moreover, Russia's official exchange rate is determined in this market once per day. Trading at this platform only 
reflects domestic trading, as there are controls on foreign exchange trading. Foreigners trade Russian roubles offshore in the form of non-deliverable forward contracts. The only participants in the domestic market are banks, but we understand that the orders put into the trading system also reflect end-user customer orders of participating banks. There is no central bank intervention during our sample period. Accordingly, the kind of information traded in this market reflects banks' research about fundamentals, their interpretation of economic policy and the dispersed information brought in by customers' demand.

Descriptive statistics. During the 9 sample days between March 11 and March 22, 2002, trading occurred only during 1 hour per day. In total, 14,109 market orders were observed, which roughly translates into 26 market orders per minute on average. As this is the domestic market, the median transaction size is only about 50,000 USD - compared with about 1 million USD in major FOREX markets (but with a similar average transaction size in stock markets). At the time, the total Russian economy only had 3\% of the US gross national product. Despite its smaller size, in comparison with the largest markets in the world, the Russian market appears to be quite efficient, as indicated by its percentage spread of 0.0071 , which is even slightly narrower than the EUR/USD market (Payne, 2003). The Russian market is also conventional with respect to market statistics (Table 1): a notable U-shaped pattern in spreads, as well as mean zero spot returns with heavy fat tails and negative first-order midquote return autocorrelation (for more detail see Menkhoff and Schmeling, 2008). All in all, the data come from a market whose characteristics match other foreign exchange markets.

Trader size. A particularly exciting feature of the data is the availability of coded trader identities. This allows us to measure the total trading volume of a trader during the sample period and we use this total trading volume as a proxy for overall trader size and the likely degree of a trader's information. Based on these statistics, each trader is allocated to 
one of three groups depending on its size, i.e. large, medium and small traders. The large trader group is designed to consist of the largest individual traders that jointly account for $25 \%$ of the total trading volume, the small trader group consists of the smallest individual traders that jointly account for $25 \%$ of the total trading volume and the medium-sized traders account for the remaining share.

Accordingly, the following statistics about these three groups show a significant degree of variation in our sample (Table 2). Although the large trader group consists of only 21 traders, it has the largest trading volume per trader (5.5 million USD) by construction - about twice as large as for medium traders and larger by a factor of 22 compared to small traders. Similar relations hold for the submitted volume of limit orders per trader in the three groups. Hence, there is lots of variation in the behavior of these trader groups and we employ this variation for our cross-sectional analyses below.

Interestingly, it can be seen that large traders do not necessarily submit the largest orders on average. More specifically, the large trader group employs an average market order size of only 58,000 USD whereas medium-sized traders, on average, submit market orders of about 64,000 USD. This is an indication that trade size may be a poor indicator to identify informed traders (also see e.g. Chakravarty, 2000).

Trader size as a proxy for information. Trader size seems to be a natural proxy for the likely degree of information of a trader. We confirm this intuition and earlier results from the literature (Cheung and Chinn, 2001) for our sample by means of standard price impact analysis. Appendix Figure A.1 shows results from a conventional Hasbrouck (1991) SVAR analysis of spot rate returns and order flows. Order flow shocks of large traders have a positive and significant long-run impact on spot rates, whereas the price impact of small traders' order flow quickly reverts to zero. This finding suggests that large traders' flows convey in- 
formation permanently incorporated into prices whereas small traders' flows only cause shortlived liquidity effects. As we observe a quite short period of time, one may hesitate to understand information in this context as information about fundamentals; it could also be information about other market participants' inventory imbalances or other trading motivations. In any case, informed (large) traders have a price impact, which makes it important to know about their trading behavior. ${ }^{1}$

Overall, this provides a reasonable basis for the goal to examine information flows between heterogeneous traders, characterized by different levels of information.

\section{Empirical approach}

In order to explore how a trader might learn from counterparties' order flow, we regress the order flow decisions of individual traders on a set of determinants that include private and public information. These determinants are motivated by earlier studies as mentioned in the introduction of this paper. They are captured by the following variables in our regression approach, which has the following baseline specification

$$
\mathrm{x}_{\mathrm{k}}^{\mathrm{i}}=\alpha^{\mathrm{i}}+\beta_{1} \mathrm{x}_{[\mathrm{k}-1]}^{\mathrm{i}}+\beta_{2} \mathrm{x}_{[\mathrm{k}-1]}^{\mathrm{i}} \cdot \lambda_{[\mathrm{k}-1]}^{\mathrm{i}, \mathrm{C}}+\gamma \mathrm{x}_{\mathrm{k}-1 ; \mathrm{t}}^{\mathrm{A}}+\delta \mathrm{r}_{\mathrm{k}-1}+\xi_{\mathrm{k}}
$$

where the dependent variable $\mathrm{x}_{\mathrm{k}}^{\mathrm{i}}$ is the order flow of trader $i$ at time $k$ (k measures event time). We include a trader-specific intercept $\left(\alpha^{\mathrm{i}}\right)$ as a means to capture trader-specific buying and selling behavior. For example, a trader or bank with an end-user customer base mainly consisting of export firms will more than likely be a seller of foreign currency, on average, while banks or traders from regions with many importers will tend to buy. Therefore, the in-

\footnotetext{
${ }^{1}$ So we follow a different direction from that of Menkhoff and Schmeling $(2008,2010)$. Whereas these papers analyze the price impact of different traders, we analyze how individual traders react to the trades of other traders.
} 
dividual constant is an approximate way of capturing such effects and it is easily implemented in a panel fixed-effects specification.

Discussion of explanatory variables. The first explanatory variable, the trader's last own order flow (denoted as $\mathrm{x}_{[\mathrm{k}-1]}^{\mathrm{i}}$ ), serves to capture persistence effects induced by (unobserved) prior information as described above. Therefore, it is not unlikely that traders will trade in the same direction over longer periods of time (this could, for example, reflect a persistent unwinding of inventory or repeated trades with end-customers in the same direction). In our basic setting, $\mathrm{x}_{[\mathrm{k}-1]}^{\mathrm{i}}$ comprises both past market orders of trader $i$ as well as this trader's executed limit orders, i.e. market orders of this trader's counterparties. ${ }^{2}$ Executed limit and market orders enter $\mathrm{x}_{[\mathrm{k}-1]}^{\mathrm{i}}$ as the positive (negative) volume of trade [k-1] when trader $i$ was the buyer (seller). We expect this variable to be positively related to the current trading decision as argued above.

The second explanatory variable (denoted as $\mathrm{x}_{[\mathrm{k}-1]}^{\mathrm{i}} \cdot \lambda_{[\mathrm{k}-1]}^{\mathrm{i}, \mathrm{C}}$ ) serves to capture the information obtained from trade disclosure by the interaction of the previous own order flow with the trader size of the counterparty. $\lambda_{[\mathrm{k}-1]}^{\mathrm{i}, \mathrm{C}}$ is a measure of the size of the last counterparty, which equals one (zero) for the largest (smallest) trader in our sample. The remaining traders are distributed between zero and one proportionally to their total trading volume over all the days in our sample. Note that $\lambda$ measures the size of a trader and not of a trade. This is important since traders practice stealth trading (Bernhardt and Hughson, 1997, Chakravarty, 2000). Also in our sample trade sizes are clustered around a "normal" amount, here 50,000 USD (see above), so that informed trade is not easily revealed by the size of a trade.

\footnotetext{
${ }^{2}$ This paper only considers all the orders that are executed immediately, i.e. market orders. Market and executed limit orders are split up later in the paper. We do not consider the placement of ordinary limit orders.
} 
As can be seen from the superscript $i$, the order flow and counterparty information is trader-specific so that only those past trades impact upon a trader's decision through the second term on the RHS in (1) where the trader actually participated in a transaction. If signals from large - and presumably informed traders - are more informative than trades from small traders, the interaction variable should capture this effect of identity disclosure. We expect this variable to have a negative sign, meaning that trading against a larger trader leads to a subsequent revision of one's own trading direction in line with the informed trader.

The third explanatory variable $\left(\mathrm{x}_{\mathrm{k}-1 ; \mathrm{t}}^{\mathrm{A}}\right)$ measures aggregate and publicly observable order flow, over the last trading minute. This variable essentially captures market-wide order flow trends and should have a positive coefficient since it is well known from the literature that order flow forecasts returns (see e.g. Payne, 2003 for FX markets).

The fourth explanatory variable included is lagged returns $\left(\mathrm{r}_{\mathrm{k}-1}\right)$ over the last trading minute to control for possible bandwagon effects and to control for possible learning about fundamental asset values from publicly available past returns.

Finally, all the order flow measures mentioned above are in terms of volume (and not as an order flow indicator ${ }^{3}$ ) and, for ease of interpretation, all the variables are standardized.

In the following analysis, we will estimate the above equation on the sample of all traders and three sub-samples, covering large, medium and small traders. The estimation is carried out using fixed-effects panel regressions so that each trader $i$ has an individual intercept $\alpha^{i}$ but all the slope coefficients are restricted to being equal across traders. More specifically, since we have lagged values of $\mathrm{x}_{\mathrm{k}}^{\mathrm{i}}$ on the RHS of the regression, we employ the GMM esti-

\footnotetext{
${ }^{3}$ We focus on order flow volume rather than an order flow indicator (see e.g. Bjønnes and Rime, 2005) to capture both the trading direction and volume effects. A trader might well adjust his trading volume without changing the direction of his trades. Therefore, using order flow volumes seems more general than just focusing on trading directions with an order flow indicator.
} 
mator for dynamic panel data (Arellano and Bond, 1991, Arellano and Bover, 1995). Inference in the paper is based on robust standard errors from these GMM regressions.

Sample adjustments. It should be mentioned that the regressions below do not include all 14,109 market orders, as documented in Table 2, for 2 reasons. First, the lagged order flows and returns were measured over intervals of 1 minute. Since all the overnight observations were eliminated, there is a loss of observations at the start of each day (roughly 1,100 observations in total). Second, all the trades of a trader executed within 10 seconds after his last trade are excluded since a trader needs some time to find out about his counterparty from this market's e-mail messaging system. It should be noted that longer and shorter (e.g. 5 seconds) intervals do not change the qualitative findings below. This procedure also makes sense economically. If a trader submits a series of trades within a short time period, it is very likely that this string of trades will represent one big order of this trader and that the decision to place this order was taken prior to submitting the first trade. We therefore do not expect to neglect important information by imposing the "10 seconds" rule. ${ }^{4}$ Owing to these two adjustments, a sample of roughly 9,700 trades remains, which still yields sufficient degrees of freedom to carry out the analysis.

\section{Main results}

The results are presented in the following order: we start with the aggregated analysis showing that the average trader significantly reacts to her counterparty (Section 4.1). We then present disaggregated results for traders of different size groups (Section 4.2). The results are extended in Sections 4.3 and 4.4.

\footnotetext{
${ }^{4}$ We do not eliminate trades from the aggregate order flow measure, of course. We also do not subtract individual from aggregate order flow for a given trader $i$.
} 


\subsection{Reaction of the average trader}

We first estimate variants of Eq. (1) above on the panel of all traders. As discussed in the last section, the "last own order flow" (or "LOOF") $x_{[\mathrm{k}-1]}^{\mathrm{i}}$ in Eq. (1) can be interpreted as a crude determinant of a trading decision partially revealing the private information of a trader. We recognize, of course, that there are also random influences on the last trade caused by liquidity traders etc. but it is sufficient for our argument that the last own trade is related to the private information of a trader.

Turning to the results, it can be seen that the actual trade is significantly influenced by the direction and size of the last trade. The coefficient for this determinant is positive, as expected, and statistically significant (see column (i) in Table 3). The estimated coefficient of 0.21 seems economically significant as well, since it implies that a one standard deviation rise in the last own order flow leads to a 0.21 standard deviation higher order flow in the current trade.

Next, we estimate the impact of lagged market-wide order flow trends and lagged returns on current individual trading decisions. These two variables represent public information to the market. Column (ii) in Table 3 shows that both coefficients are positive as theoretically expected but that only lagged order flow is statistically significant. These effects of past aggregate order flow (or returns) on current order flow are not new to the literature (see e.g. Hasbrouck, 1991, or Payne, 2003) but we stress that we are - to the best of our knowledge the first to conduct such an analysis on the micro-level of all individual traders in a market.

As a third variant of Eq. (1), we now estimate the impact of post-trade identity disclosure by interacting the variable of the last own order flow, LOOF, with the size of the counterparty $\lambda$. The empirical effect of this variable is shown in column (iii): the coefficient of the 
interaction variable is negative, as theoretically expected, and significant. ${ }^{5}$ This suggests that order flow directions and magnitudes spill over from past counterparties' trades as may be intuitively expected. The estimated coefficient of -0.173 is about $70 \%$ of the (absolute) size of the coefficient of the last own order flow (estimated to be 0.257 ). This result implies that the positive autocorrelation (as measured by LOOF) is reduced by about $70 \%$ when the last counterparty was a very large trader while it is increased by about $70 \%$ when the last counterparty was a very small, and presumably uninformed, market participant. This reliance on information gained by post-trade identity disclosure suggests an important role for individual learning from order flow and, in particular, that large traders' order flow is highly important for price discovery. We believe that this finding is an important contribution of our paper, since it illuminates and quantifies the way in which traders incorporate order flow information into prices in real time.

Finally, all determinants keep their signs and significance levels in a joint specification, indicating that our basic results are robust to variations in the specific regression setup (column (iv) in Table 3).

The table also shows the fraction of variance of the dependent variable due to individual fixed effects (labeled $\tau$ in the table). This fraction is sizeable and ranges from 20 to $35 \%$, indicating that individual trader heterogeneity is important.

The main finding to take away from this section is that traders react significantly to large counterparties' order flow even when controlling for market-wide order flow and exchange rate returns.

\footnotetext{
${ }^{5}$ We show results for order flow volume here, i.e. the negative coefficient sign means that traders reduce their order flow after a positive order flow shock from an informed counterparty. We have also experimented with binary choice models (not reported for the sake of brevity) and find that the prob-
} 


\subsection{Reaction of large, medium and small traders}

This section shows that traders of different size groups react in a specific way to the available private and public information. The pattern that emerges appears to be compatible with rational behavior.

We rely on the empirical framework introduced above but estimate our regressions on the sub-samples of different trader groups. The cross-section of all traders is split into large-, medium- and small-sized traders, as documented in Section 3 above (see Table 2). The results in Table 4 show that the estimated coefficient signs are unchanged compared to our findings above. However, the absolute magnitudes of several determinants change quite a bit. Large traders' behavior seems to be best understood by relying on all three explanatory variables. These determinants have the expected coefficient signs and are statistically significant. The relatively weakest determinant - with regard to coefficient size and level of significance seems to be the interaction term that indicates that large traders learn less from other traders' order flow than the average market participant (see Table 3), a result that seems economically intuitive.

Turning to the smallest traders, they react strongly to their last counterparty, indicating that they learn a lot from their counterparties' order flow. Compared with large traders, they do not react strongly to lagged order flow and returns in the market, i.e. publicly available information. The estimated coefficients are small in magnitude and the statistical significance is only borderline. This may be a rational stance for those market participants who are less active in the market and thus generally care less about recent price and order flow trends.

Finally, looking at the medium-sized traders, they behave in a way that lies somewhere in between large and small traders. Regarding their own order flow and the market-wide

ability of changing the trading direction increases significantly. Therefore, traders tend to reverse their trading direction, as claimed in the text. 
lagged order flow, they are closer to the large traders, but regarding the interactive term, they seem to be closer to the small traders. ${ }^{6}$

The results documented above seem interesting since they imply that information is aggregated into prices in a different way by different subgroups of heterogeneous traders and that trader size seems to be a useful way to categorize traders. In particular, large vs. small traders seem to perform different roles in the price discovery process: large traders quickly incorporate public and their private information whereas small traders rely relatively more on information gained during the trading process and, thereby, amplify the actions from larger and presumably more informed traders.

\subsection{Importance of the disaggregated traders' reaction}

We examine the interaction and learning behavior of traders in three additional ways: (a) how do traders react to order flow over time, (b) what role does order size play and (c) what is the relative importance of public and private information.

How important is the reaction over time? We extend the above analysis and analyze learning over longer horizons. To tackle this question, sequences of equations that differ only by the timing of the dependent variable are estimated:

$$
\mathrm{x}_{\mathrm{k}+\mathrm{j}-1}^{\mathrm{i}}=\alpha_{\mathrm{j}}^{\mathrm{i}}+\beta_{1, \mathrm{j}} \mathrm{x}_{[\mathrm{k}-1]}^{\mathrm{i}}+\beta_{2, \mathrm{j}} \mathrm{x}_{[\mathrm{k}-1]}^{\mathrm{i}} \cdot \lambda_{[\mathrm{k}-1]}^{\mathrm{i}, \mathrm{C}}+\gamma_{\mathrm{j}} \mathrm{x}_{\mathrm{k}-1 ; \mathrm{t}}^{\mathrm{A}}+\delta_{\mathrm{j}} \mathrm{r}_{\mathrm{k}-1}+\xi_{\mathrm{k}, \mathrm{j}}
$$

i.e. we estimate equation (1) for subsequent trading decisions $j=1,2, \ldots, 6$, in event time. This approach projects future order decisions on current measures of information and allows us to study how long it takes for information from the most frequent order flow to be fully incorporated into individual trading decisions. The sequence of coefficient estimates $\beta_{1, j}, \beta_{2, j}$ can then be used directly to construct impulse responses in the spirit of Jordá (2005).

\footnotetext{
${ }^{6}$ The standard errors of coefficient estimates generally do not imply a statistically significant differ-
} 
The results from these local projections can be found in Figure 1. Panel A shows results for a scenario where the last trade occurred with a completely uninformed trader, i.e. $\lambda^{\mathrm{C}}=0$, and Panel B shows a scenario where the last counterparty is highly informed, i.e. $\lambda^{\mathrm{C}}=1{ }^{7}$ As can be seen from Panel A, the last own order flow is a significant and positive determinant of future trading decisions when the last counterparty was small and thus little can be learned from counterparty order flow. There is significant autocorrelation in individual trading decisions for two periods.

Contrary to this, Panel B shows that large and presumably informed counterparties have a significant impact on traders' order decisions. While the direct impact on the next trade seems dominated by own past trading decisions, it is obvious from this figure that information gained from past counterparties is fairly persistent and leads to a significant reversal of trading directions after only about three trades.

Similarly, learning effects over time for the different trader groups are shown in Figure 2. This figure is analogous to Figure 1 above, but displays results separately for the three different trader groups. As can be seen from Panel A of Figure 2, trading decisions are most heavily autocorrelated for small and medium-sized traders when the last counterparty was small, i.e. uninformed. Large traders show less autocorrelated trading behavior. Panel B shows the results for the case when the last trade occurred with an informed counterparty. In that case, large traders do not adjust their trading behavior over time, whereas small and medium-sized traders strongly adjust, or rather reverse, their previously taken trading directions. Therefore, effects over time are consistent with the one period of results shown in Table 4.

ence between the three groups. The groups are, however, clearly different in economic terms.

${ }^{7}$ Numbers underlying Figure 1 are calculated as $\hat{\beta}_{1, j}$ for the case of an uninformed last counterparty and as $\hat{\beta}_{1, j}+\hat{\beta}_{2, j}$ for the informed last counterparty with $j=1,2, \ldots, 6$. All other explanatory variables are set to their mean value (which is zero due to the standardization of explanatory variables). 
This analysis also shows that the negative coefficient estimate of "LOOF $\times$ size" e.g. in Tables 3 and 4 does not simply imply that traders reduce their order size but tend to keep their former trading direction. Figures 1 and 2, Panel B, clearly show that traders do actually reverse their trading direction after trading against an informed trader.

How important is order size? One may argue that our counterparty size variable $\lambda^{\mathrm{C}}$ just proxies for order size. If larger traders (higher $\lambda^{\mathrm{C}}$ ) use larger order sizes, then a negative coefficient on the interaction variable $\left(\mathrm{x} \times \lambda^{\mathrm{C}}\right)$ does not need to imply learning effects but just a non-linearity in the autoregressive behavior of individual order flows: traders reduce their trading volume after large trades. As we have argued in Section 3, this is unlikely due to the fact that especially the larger traders in our sample rather use medium-sized orders and follow order-splitting strategies. However, we provide a more direct test by running the following regression:

$$
\mathrm{x}_{\mathrm{k}}^{\mathrm{i}}=\alpha^{\mathrm{i}}+\beta_{1} \mathrm{x}_{[\mathrm{k}-1]}^{\mathrm{i}}+\beta_{2} \mathrm{x}_{[\mathrm{k}-1]}^{\mathrm{i}} \cdot\left|\mathrm{x}_{[\mathrm{k}-1]}^{\mathrm{i}}\right|+\beta_{3} \mathrm{x}_{[\mathrm{k}-1]}^{\mathrm{i}} \cdot \lambda_{[\mathrm{k}-1]}^{\mathrm{i}, \mathrm{C}}+\gamma \mathrm{x}_{\mathrm{k}-1 ; \mathrm{t}}^{\mathrm{A}}+\delta \mathrm{r}_{\mathrm{k}-1}+\xi_{\mathrm{k}}
$$

which - compared with (1) - includes the last own order flow interacted with the last order size (the absolute last own order flow, $|\mathrm{x}|)$ as an additional explanatory variable. If our results are really driven by learning from post-trade transparency, then the interaction term for trader size should remain a significant determinant of individual order flows. The results for this regression for all traders, large, medium-sized and small traders are shown in Table 5.

As these results show, there is little evidence that the last counterparty's identity simply proxies for order size. The coefficient estimate of $\beta_{2}$ is negative but not significant for the sample of all traders. It only seems to capture some non-linearity in the autoregressive behavior of individual order flow for medium-sized (marginally significant) and small traders (significant at the 5\% level). However, even for these two trader groups, the interaction term 
of last own order flow and order size does not drive out the interaction term with the size of the last counterparty. Therefore, counterparty size does indeed matter.

How important is private versus public information? Our results above so far show that both private (post-trade transparency) and public (aggregate order flow) information have an impact on individual trading decisions. To shed further light on this issue, we analyze whether the availability of private information from post-trade transparency reduces the impact of public information on a trader's order flow decision. Such a result may be expected if post-trade identity disclosure provides more precise information than aggregate order flow, since the latter does not discriminate between informed and uninformed traders. In the presence of private information, traders could rationally place less weight on public information, which is less precise.

We therefore augment our base specification in (1) with an interaction term of aggregate order flow $\left(\mathrm{x}^{\mathrm{A}}\right)$ and the size of the last counterparty $\left(\lambda^{\mathrm{C}}\right)$ and estimate the panel fixed-effects regression

$$
\mathrm{x}_{\mathrm{k}}^{\mathrm{i}}=\alpha^{\mathrm{i}}+\beta_{1} \mathrm{x}_{[\mathrm{k}-1]}^{\mathrm{i}}+\beta_{2} \mathrm{x}_{[\mathrm{k}-1]}^{\mathrm{i}} \cdot \lambda_{[\mathrm{k}-1]}^{\mathrm{i}, \mathrm{C}}+\gamma_{1} \mathrm{x}_{\mathrm{k}-1 ; \mathrm{t}}^{\mathrm{A}}+\gamma_{2} \mathrm{x}_{\mathrm{k}-1 ; \mathrm{t}}^{\mathrm{A}} \cdot \lambda_{[\mathrm{k}-1]}^{\mathrm{i}, \mathrm{C}}+\delta \mathrm{r}_{\mathrm{k}-1}+\xi_{\mathrm{k}}
$$

which is otherwise unchanged. A negative (positive) estimate of $\gamma_{2}$ would imply that traders rely less (more) on aggregate order flow after trading against informed traders and vice versa. Estimation results for the sample of all traders and the sub-samples of large, medium-sized and small traders are given in Table 6.

The results show that the coefficient on the new interaction term is significantly negative for all traders, which means that counterparty information lowers traders' reliance on public information. The coefficient on the interaction term $\left(\gamma_{2}\right)$ is about $25 \%$ of the coefficient on aggregate order flow $\left(\gamma_{1}\right)$, implying that the impact of the latter is reduced by about one fourth. 
However, information about the counterparty does not reduce reliance on public order flow trends completely. This fact is also underscored by the disaggregated results for the three trader groups sorted by size. The interaction term is not significant for large traders and hardly significant for the small traders, so that most of the effect discussed above stems from the group of medium-sized traders. Therefore, public information seems to be an important determinant of individual trading behavior that is reduced but not driven out by reaction to large traders.

\subsection{Separating market and limit orders}

We now consider limit orders in addition to the market orders analyzed so far. We recognize that basic insights extend from market orders to limit orders but that market orders are more informative.

This analysis serves to investigate the following question: do traders learn more from executed limit orders (i.e. the counterparty used a market order) or from market orders (i.e. the counterparty originally submitted a limit order)? The literature usually assumes that private information is primarily revealed by market orders (see e.g. the discussion in Kaniel and Liu, 2006), thus a natural hypothesis would be that order flow from own limit orders (i.e. counterparty's market orders) should have a stronger impact than own market orders (i.e. the counterparty originally submitted a limit order).

Table 7 shows that this is, indeed, the case. Looking first at the results for all traders jointly, it can be seen that the effect of the last counterparty's trade impacts on a trader's order flow decision more heavily when the last counterparty used a market order relative to a counterparty originally submitting a limit order. Nevertheless, it should be noted that there is a significant effect for both limit and market order flow from the last counterparty. This result 
strongly suggests that traders learn from the market and limit orders of their counterparties and it rejects the view that information is conveyed by market orders only. This finding complements earlier results by Kaniel and Liu (2006) and Bloomfield et al. (2005), who also find that limit orders are informative for future price movements and that informed traders do indeed use limit orders, respectively.

Estimates for the three different groups of traders in Table 7 again show that large traders react least to information gained by observing the identity of counterparties, irrespective of whether the last counterparty used a market order or limit order. Also, all trader groups learn more from their last counterparty's trade when the counterparty used a market order compared with a limit order. The only difference between the three groups seems to be the relative size of their reaction coefficients.

\section{Robustness tests}

This section undertakes several tests to check robustness of the results. We show that our results do not depend (a) on the time period of trader classification, (b) on very short trade durations, (c) on the measure of a cumulated order flow, (d) on the measure of an order flow indicator (instead of volume), (e) on the inclusion of time-of-the-day dummies, (f) on certain states of the market, e.g. high versus low trading volume or bid-ask spreads, (g) on estimating the main regression on two different kinds of sub-samples and (h) some further modifications.

Trader classification. A possible shortcoming of our empirical approach so far is the fact that the classification of traders according to their trading volume is based on trading over the whole sample period. Therefore, we rely on the assumption that a trader's volume relative to other traders remains fairly constant over time and has already been learned by market participants in the past. This assumption seems reasonable since the trader population is not too 
large and variable, so that relying on an in-sample estimate of trader size that uses all available information will most probably be least noisy. However, one may also be interpreted in a setup where trader size is estimated from data that is not used in our regression analyses. Thus we provide two further analyses where trader classification is based on a pre-sample period.

In the first case, we rely on data from an available sample period ranging from March 1 to 7 which we use for trader classification only and then re-estimate our main results using this alternative trader size proxy on data from March 11 to March 21 as above. The earlier data is not used in this paper otherwise, because the central bank intervenes in the market during these days and trading in this intervention period is clearly dominated by the central bank and very different from non-intervention days. Thus, we only use these earlier data to check for robustness of our trader size proxy.

Since there it seems possible that traders behave differently during intervention and non-intervention times, we also consider a second case and split our original sample into two sub-samples. Then, the first days from March 11 to 15 are only used to construct the proxy for trader size and the second sub-period, i.e. March 18 to 22 is used to estimate our main regression specifications. As expected, trader size is highly positively correlated with the original trader size proxy in both cases we consider (the correlation coefficients are 0.87 and 0.74 , respectively).

$\underline{\text { Table } 8}$ provides the new regressions results, where the benchmark specification (iv) of former table 3 is repeated with the different trader classification. Reassuringly, results remain remarkable stable with respect to coefficient signs, sizes and significance.

Trade durations. We now aim at quantifying the impact of trade durations on individual trading. It seems intuitive that information about past counterparty identities loses value over time. We therefore estimate how long counterparty information affects individual order 
flow decisions. To do this, we augment our base specification in (1) by two interaction terms, and the regression now reads

$$
\begin{aligned}
\mathrm{x}_{\mathrm{k}}^{\mathrm{i}}=\alpha^{\mathrm{i}} & +\beta_{1} \mathrm{x}_{[\mathrm{k}-1]}^{\mathrm{i}}+\beta_{2} \mathrm{x}_{[\mathrm{k}-1]}^{\mathrm{i}} \cdot \mathrm{d}_{[\mathrm{k}-1]}^{\mathrm{i}} \\
& +\beta_{3} \mathrm{x}_{[\mathrm{k}-1]}^{\mathrm{i}} \cdot \lambda_{[\mathrm{k}-1]}^{\mathrm{i}, \mathrm{C}}+\beta_{4} \mathrm{x}_{[\mathrm{k}-1]}^{\mathrm{i}} \cdot \lambda_{[\mathrm{k}-1]}^{\mathrm{i}, \mathrm{C}} \cdot \mathrm{d}_{[\mathrm{k}-1]}^{\mathrm{i}} \\
& +\gamma_{1} \mathrm{x}_{\mathrm{k}-1 ; \mathrm{t}}^{\mathrm{A}}+\gamma_{2} \mathrm{x}_{\mathrm{k}-1 ; \mathrm{t}}^{\mathrm{A}} \cdot \lambda_{[\mathrm{k}-1]}^{\mathrm{i}, \mathrm{C}}+\delta \mathrm{r}_{\mathrm{k}-1}+\xi_{\mathrm{k}}
\end{aligned}
$$

so that the last own order flow (x) and the interaction term with counterparty size $(\mathrm{x} \cdot \lambda)$ are both interacted with a trade duration variable $\mathrm{d}^{\mathrm{i}}$. This trade duration measures elapsed time (in minutes) since the last trade of trader $i$ and the interaction with $\mathrm{d}$ allows us to test how the direct autoregressive behavior of individual order flow changes for longer trade durations (via $\beta_{2}$ ). Similarly, it also allows us to test whether the effect of counterparty information on autocorrelated trading behavior of individuals changes over time (via $\beta_{4}$ ). Intuitively, we would expect both $\beta_{2}$ and $\beta_{4}$ to be negative, since sooner trades should be less informative for current behavior.

Results are shown in Table A.1 and we find that the effect of trade durations on the general autocorrelation in order flows is not significantly different from zero. Therefore, autocorrelated trading - or order splitting - seems to be quite persistent. We find, however, that the effect of trade durations on learning from identity disclosure is positive and significant for the market as a whole and for small and medium-sized traders. A positive coefficient means that counterparty information loses value as time elapses.

The size of the estimated coefficients suggests that the impact of counterparty information vanishes completely after about 2.5 minutes $^{8}$ (for the joint regression including all trad-

\footnotetext{
${ }^{8}$ The coefficient estimate of $\beta_{3}$ is -0.189 , whereas we estimate $\beta_{4}$ to be 0.076 . Therefore, the effect of LOOF $\times$ size vanishes after $0.189 / 0.076 \approx 2.5$ minutes.
} 
ers), which still implies a large role for counterparty information since there are several trades per minute in the market under study.

Also, the effect of counterparty information dies out more slowly for small and medium-sized traders, as may be expected. Our estimates imply that counterparty information is essentially uninformative after $0.511 / 0.112 \approx 4.5$ minutes for medium-sized traders and after $0.714 / 0.093 \approx 7.7$ minutes for small traders. There is no significant effect of trade durations for large traders. This may stem from the fact that the impact of counterparty information does not seem to be important for large trades in the first place.

All in all, there is evidence that counterparty information decays over time. However, it seems to be valuable for several minutes, which indicates that it has quite an impact on trading behavior - especially by medium-sized and small traders.

Cumulative order flows. Turning to the measure of order flow, we have up to now used information from the last trade of a given trader. While this seems a natural starting point, it is also interesting to extend the information set of traders beyond the last trade. For this reason, a measure of cumulated, trader-specific order flows that cumulates all the trades of a given day is also computed. The base regression (1) now reads:

$$
\mathrm{x}_{\mathrm{k}}^{\mathrm{i}}=\alpha^{\mathrm{i}}+\beta_{1} \tilde{\mathrm{x}}_{[\mathrm{k}-1]}^{\mathrm{i}}+\beta_{2} \theta_{[\mathrm{k}-1]}^{\mathrm{i}}+\gamma \mathrm{x}_{\mathrm{k}-1 ; \mathrm{t}}^{\mathrm{A}}+\delta \mathrm{r}_{\mathrm{k}-1}+\xi_{\mathrm{k}}
$$

where $\tilde{\mathrm{x}}_{[\mathrm{k}-1]}^{\mathrm{i}}$ denotes the cumulated order flow of trader $i$ just prior to the actual trade $k$. Order flow is cumulated on a day-by-day basis so that $\tilde{\mathrm{x}}_{[\mathrm{k}-1]}^{\mathrm{i}}$ starts with a value of zero each day when the trading session opens. The interaction term is denoted by $\theta_{[\mathrm{k}-1]}^{\mathrm{i}, \mathrm{C}}=\sum_{\mathrm{h}=1}^{\mathrm{k}-1} \mathrm{x}_{[\mathrm{h}]}^{\mathrm{i}} \cdot \lambda_{[\mathrm{h}]}^{\mathrm{i}, \mathrm{C}}$ so that every single order flow of a given day is weighted by that counterparty's size and summed up over the day. We report results in Table A.2. 
The estimates for all traders show that our findings above are robust to this modification of the order flow measure. Traders still significantly tend to follow their previous trading direction, and they still tend to switch their trading direction when their last counterparty was a large trader. Also, results for the three trader groups are qualitatively very similar to the findings reported above. Large traders tend to rely less on their earlier trading decisions and less on the information contained in privately observed trades, but tend to follow aggregate order flow movements more strongly. In contrast to this, small traders adhere to their own information and the information gained by trade disclosure more heavily than large traders.

Moreover, we run regressions where we split up the total past cumulated own order flow into two components by separating the last own order flow from the remaining cumulated own order flow, i.e. we include $\tilde{\mathrm{x}}_{[\mathrm{k}-2]}^{\mathrm{i}}$ and $\mathrm{x}_{[\mathrm{k}-1]}^{\mathrm{i}}$ (and interactions with counterparty size thereof) separately as explanatory variables. Results are not qualitatively different from our earlier analyses. We mention that the most recent own order flow (i.e. $x_{[k-1]}^{i}$ ) has a stronger effect on current trading decisions than cumulated past flows.

Order flow indicators. So far we have used an order flow measure based on the volume of order flow. Some studies have argued, however, that simple order flow indicators may be at least as useful as the volume-based measure (e.g. Jones, Kaul and Lipson, 1994; Chordia and Subrahmanyam, 2004). Hence, we repeat our analyses by relying on order flow indicators which equal one for positive order flow and zero otherwise.

We employ a panel logit model to capture the binary nature of the dependent variable and also use order flow indicators for the regressors. Results in Table A.3 show that our main conclusions in term of economic effects and statistical significance are unchanged by considering indicators instead of volumes. 
Time-of-the-day dummies. Foreign exchange markets in general are characterized by clear intraday seasonality patterns in trading activity and our market is no exception (see Table 1). In order to control for possible effects from such intraday patterns, we repeat our baseline regression and add five time-of-the-day dummies which are equal to one in one of the first five ten minutes intervals of trading in each session each. ${ }^{9}$ Results for all traders and the three size subgroups are reported in Table A.4 and show that intraday seasonalities do not seem to be important when looking at individual order flow volumes. None of the time dummies is individually significant and a joint test of significance also does not reject the null of zero coefficients in any case. Thus, it seems that we have clear seasonal patterns in trading activity but not in trading direction which is what drives our results in these regressions.

Market states. Next, we control for the possible impact of market conditions, such as trading volume, bid-ask spreads and return volatility, as market states may impact trading behavior or market outcomes (e.g. Evans and Lyons, 2002a; Hasbrouck and Saar, 2009). Therefore, the sample is split into times of high and low (lagged) trading volume, bid-ask spreads and return volatility. To do this, we calculated the three statistics over periods of one minute, deseasonalized the series and split the total sample along the median value of each of the three measures. ${ }^{10}$ Then, equation (1) is estimated for these sub-samples and we report results of this exercise in Table A.5.

For trading volume, results suggest that LOOF has a larger impact when lagged trading volume is high, meaning that the autocorrelation of individual traders' orders are larger when

\footnotetext{
${ }^{9}$ We have experimented with other specifications to capture intraday seasonalities such as polynomials of a continuous time variable etc. Results reported in the following are unchanged in these cases, though.

${ }^{10}$ More specifically, at each observation $k$, the three measures were computed over an interval of one minute prior to $k$ (and excluding observation $k$ ). The resulting series of trading volumes, spreads and volatilities are then regressed on twelve five-minute dummies for the time of the trading session to net out intraday seasonalities. The residuals of these regressions are then used to split the sample along the respective medians.
} 
the market has been very active. In contrast to this, there is less reaction to trades of the counterparty in times of high volume compared with low volume periods. This result suggests that the information contained in other traders' trades is less valuable when the market is active. This is in line with early theoretical models where high trading volume suggests the presence of noise trading that is rather uninformative for fundamental asset values (e.g. Admati and Pfleiderer, 1988; Campbell, Grossman and Wang, 1993).

Results for lagged bid-ask spreads suggest that traders pay particular attention to other traders' trades and publicly observable order flow when the spread is high. This result corroborates theoretical conjectures that a high spread signals a high likelihood of informed trade (e.g. Easley and O’Hara, 1987). Earlier empirical evidence (e.g. Payne, 2003) has, indeed, shown that the price impact of order flow is higher in times of high spreads and vice versa. Our result suggests that this higher price impact may stem from greater willingness to reverse the trading direction in response to larger traders.

Next, results for lagged midquote return volatility are similar to the results for spreads, although the differences between periods of high and low volatility are less pronounced than they are for spreads. The similarity to the results for spreads seems natural since spreads and volatility are correlated and as high volatility is also taken to be a sign of information processing and thus a signal of informed trade.

Sub-sample analysis. Finally, we carry out some sub-sample analyses. First, we run our base regression in (1) separately on data ranging from March 11 to March 15 and from March 18 to 21, respectively. Second, we rerun the regression on the first 15 minutes and on the last 45 minutes of the trading session, respectively. We do this, since roughly $50 \%$ of the trades in our sample occur in the first 15 minutes and it thus seems interesting to check whether the results differ between the early and later parts of the trading session. 
Results for these sub-sample analyses are shown in Table A.6. As can be seen from the table, both ways of splitting our sample suggest that the qualitative results are not sensitive to a certain time period but rather seem pretty stable.

Further tests. Apart from the robustness checks documented here, we also perform a number of additional (untabulated) tests. These additional tests include methodological and economic robustness tests. With regard to the former, pooled regressions were used instead of fixed effects and we also experimented with regressions where equation (1) was estimated separately for each trader in the sample so that both intercepts and slope coefficients were allowed to vary across traders. However, the results are robust to these variations. With regard to additional economic robustness tests, different trader group classifications were used instead of the 25/50/25 scheme. Again, the results are similar to those reported in the paper.

\section{Conclusions}

Our study examines how individual traders react to their counterparties by analyzing counterparties' direction and size of order flow.

The database for this research comprises a short but completely documented sample period in the Russian rouble vs. US dollar limit order market during March 2002. The main advantage of these data is the availability of anonymous trader identities. This allows for an analysis of the determinants of several hundred individual traders' buying and selling decisions in an unusually detailed approach. In addition, the trading statistics provide information about the total transaction volume of each trader, and this is used as a proxy for the likely degree of a trader's information.

Our main finding is that traders significantly react to the identity of their last counterparty in that they tend to reverse their trading direction if their last counterparty was a larger 
and thus better informed trader. This finding holds when controlling for other trading determinants, whose impact seems interesting in itself: an individual trader's direction and volume of trading is positively autocorrelated, indicating reliance on private information; moreover, a trader's trading is positively related to lagged trends in market momentum, indicating the use of publicly available information. Interestingly, the effect from informed counterparty order flow is so strong that it leads to a statistically significant reversal of the former own trading direction. In our sample, this is estimated to occur after about one or two further trades.

Further disaggregated analyses provide a second finding about the price discovery process. In particular, large and small traders differ in their use of information: all traders rely on their private information, but whereas large traders react strongly to and thus process publicly available information, small traders react more strongly to the trades with larger counterparties. The relevance of counterparty information is further corroborated by showing that counterparty information tentatively drives out the importance of public information as a determinant of individual trading decisions. The findings are essentially confirmed when we complement the earlier analyses of market orders by also considering limit orders. Our main results also hold when we control for market states, split the sample and use other definitions and methods.

Overall, this research presents an unusually detailed picture of the price-discovery process in a modern limit order market. It also cautiously indicates a policy implication in the sense that the revelation of counterparties especially benefits uninformed traders, since these traders seem to learn most from counterparty identities (see e.g. Bloomfield and O'Hara, 1999, Madhavan et al., 2005). Identity disclosure may also contribute to market efficiency as learning amplifies the impact of informed traders and thus leads to a faster dissemination of 
order flow information. However, there may be a balancing effect when informed traders adjust their trading behavior in order to avoid these revelation "costs." 


\section{References}

Admati, A.R., Pfleiderer, P., 1988. A theory of intraday trading patterns: Volume and price variability. Review of Financial Studies 1, 3-40.

Ahn, H.-J., Bae, K.-H., Chan, K., 2001. Limit orders, depth, and volatility: Evidence from the stock exchange of Hong Kong. Journal of Finance 56, 767-788.

Arellano, M., Bond, S., 1991. Some tests of specification for panel data: Monte Carlo evidence and an application to employment equations. Review of Economic Studies 58, 277-292.

Arellano, M., Bover, O., 1995. Another look at the instrumental variables estimation of error components models. Journal of Econometrics 68, 29-52.

Back, K., Cao, C.J., Willard, G.A., 2000. Imperfect competition among informed traders. Journal of Finance 55, 2117-2155.

Bernhardt, D., Hughson, E., 1997. Splitting orders. Review of Financial Studies 10, 69-101.

Bjønnes, G.H., Rime, D., 2005. Dealer behavior and trading systems in foreign exchange markets. Journal of Financial Economics 75, 571-605.

Bjønnes, G.H., Osler, C., Rime, D., 2008. Asymmetric information in the interbank foreign exchange market. Working Paper, Norges Bank.

Bloomfield, R., O'Hara, M., 1999. Market transparency: Who wins and who loses? Review of Financial Studies 12, 5-35.

Bloomfield, R., O'Hara, M., Saar, G., 2005. The 'make or take' decision in an electronic market: Evidence on the evolution of liquidity. Journal of Financial Economics 75, 165 199.

Campbell, J.Y., Grossman, S.J., Wang, J., 1993. Trading volume and serial correlation in stock returns. Quarterly Journal of Economics 108, 905-939. 
Chakravarty, S., 2000. Stealth trading: Which traders' trades move stock prices? Journal of Financial Economics 61, 289-307.

Chari, A., 2007. Heterogeneous market-making in foreign exchange markets: Evidence from individual bank responses to central bank intervention. Journal of Money, Credit and Banking 39, 1134-1161.

Cheung, Y.-W., Chinn, M.D., 2001. Currency traders and exchange rate dynamics: A survey of the US Market. Journal of International Money and Finance 20, 439-471.

Chordia, T., Subrahmanyam, A., 2004. Order imbalance and individual stock returns: Theory and evidence. Journal of Financial Economics 72, 485-518.

Colla, P., Mele, A., 2010. Information linkages and correlated trading. Review of Financial Studies 23, 203-246.

Dominguez, K.M.E., 2003. The market microstructure of central bank intervention. Journal of International Economics 59, 25-45.

Easley, D., O'Hara, M., 1987. Price, trade size and information in securities markets. Journal of Financial Economics 19, 69-90.

Evans, M.D.D., Lyons, R.K., 2002. Order flow and exchange rate dynamics. Journal of Political Economy 110, 170-180.

Evans, M.D., Lyons, R.K., 2002a. Time-varying liquidity in foreign exchange. Journal of Monetary Economics 49, 1025-1051.

Evans, M.D., Lyons, R.K., 2008. How is macro news transmitted to exchange rates? Journal of Financial Economics 88, 26-50.

Foster, F.D., Viswanathan, S., 1996. Strategic trading when agents forecast the forecasts of others. Journal of Finance 51, 1437-1478. 
Foucault, T., Moinas, S., Theissen, E., 2007. Does anonymity matter in electronic limit order markets? Review of Financial Studies 20, 1707-1747.

Goodhart, C.A.E., 1988. The foreign exchange market: A random walk with a dragging anchor. Economica 55, 437-460.

Hasbrouck, J., 1991. Measuring the information content of stock trades. Journal of Finance 46, 179-207.

Hasbrouck, J., Saar, G., 2009. Technology and liquidity provision: The blurring of traditional definitions. Journal of Financial Markets 12, 143-172.

Ito, T., Lyons, R.K., Melvin, M.T., 1998. Is there private information in the FX market? Journal of Finance 53, 1111-1130.

Jones, C.M., Kaul, G., Lipson, M.L., 1994. Transactions, volume, and volatility. Review of Financial Studies 7, 631-651.

Jordá, Ó., 2005. Estimation and inference of impulse responses by local projections. American Economic Review 95, 161-182.

Kaniel, R., Liu, H., 2006. So what orders do informed traders use? Journal of Business 79, 1867-1913.

Lyons, R.K., 1995. Tests of microstructural hypotheses in the foreign exchange market. Journal of Financial Economics 39, 321-351.

Lyons, R.K., 2001. The Microstructure Approach to Exchange Rates. MIT Press, Cambridge.

Madhavan, A., Porter, D., Weaver, D., 2005. Should securities' markets be transparent? Journal of Financial Markets 8, 266-288.

Menkhoff, L., Schmeling, M., 2008. Local information in foreign exchange markets. Journal of International Money and Finance 27, 1383-1406. 
Menkhoff, L., Schmeling, M., 2010. Whose trades convey information? Evidence from a cross-section of traders, Journal of Financial Markets 13, 101-128.

Menkhoff, L., Taylor, M.P., 2007. The obstinate passion of foreign exchange professionals: Technical analysis. Journal of Economic Literature 45, 936-972.

Moore, M., Payne, R., 2009. Size, specialism and the nature of informational advantage in inter-dealer foreign exchange trading. Working Paper, Warwick Business School.

Osler, C.L., Mende, A., Menkhoff, L., 2006. Price discovery in currency markets. Working Paper, University of Hannover.

Parlour, C.A., Seppi, D.J., 2008. Limit order markets: A survey, in: Boot, A.W.A., Thakor, A.V. (Eds.), Handbook of Financial Intermediation and Banking, forthcoming.

Payne, R., 2003. Informed trade in spot foreign exchange markets: An empirical investigation. Journal of International Economics 61, 307-329.

Peiers, B.,1997. Informed traders, intervention, and price leadership: A deeper view of the microstructure of the foreign exchange market. Journal of Finance 52, 1589-1614.

Phylaktis, K., Chen, L., 2010. Asymmetric information, price discovery and macroeconomic announcements in FX market: Do top trading banks know more? International Journal of Finance and Economics, forthcoming.

Porter, D.C., Weaver, D.G., 1998. Post-trade transparency on Nasdaq's national market system. Journal of Financial Economics 50, 231-252.

Ramadorai, T., 2008. What determines transaction costs in foreign exchange markets? International Journal of Finance and Economics 13, 14-25.

Sager, M., Taylor, M.P., 2006. Under the microscope: The structure of the foreign exchange market. International Journal of Finance and Economics 11, 81-95. 
Table 1

Descriptive statistics

\begin{tabular}{lrrrrrrr}
\hline & $\begin{array}{c}\text { Mean } \\
\left(\times 10^{4}\right)\end{array}$ & $\begin{array}{c}\text { St. dev. } \\
\left(\times 10^{3}\right)\end{array}$ & \multicolumn{1}{c}{ Kurtosis } & \multicolumn{1}{c}{$\rho_{-1}$} & Trade size & $\begin{array}{c}\text { Number } \\
\text { of trades }\end{array}$ & $\begin{array}{c}\text { quoted } \\
\text { pct. spread }\end{array}$ \\
\hline All & 0.02 & 0.301 & 18.70 & -0.0961 & 49,396 & 14,109 & 0.0071 \\
5 & -0.01 & 0.276 & 24.65 & -0.1318 & 55,795 & 3,140 & 0.0115 \\
10 & 0.01 & 0.294 & 18.80 & -0.1070 & 52,236 & 2,404 & 0.0045 \\
15 & 0.13 & 0.289 & 16.32 & -0.1361 & 49,009 & 1,907 & 0.0043 \\
20 & -0.03 & 0.290 & 18.82 & -0.0600 & 47,362 & 1,242 & 0.0049 \\
25 & -0.09 & 0.299 & 19.03 & -0.0447 & 46,821 & 1,024 & 0.0049 \\
30 & -0.11 & 0.308 & 17.02 & -0.0132 & 39,200 & 832 & 0.0046 \\
35 & 0.04 & 0.321 & 15.96 & -0.1488 & 44,903 & 585 & 0.0050 \\
40 & 0.05 & 0.287 & 18.89 & -0.5050 & 50,000 & 760 & 0.0049 \\
45 & 0.04 & 0.352 & 14.09 & -0.0895 & 51,427 & 597 & 0.0045 \\
50 & 0.18 & 0.345 & 16.26 & -0.2230 & 42,732 & 541 & 0.0045 \\
55 & 0.18 & 0.358 & 13.32 & -0.0459 & 39,900 & 581 & 0.0059 \\
60 & -0.02 & 0.324 & 18.35 & -0.1420 & 44,429 & 496 & 0.0120 \\
\hline
\end{tabular}

This table shows descriptive statistics for RUR/USD spot returns (in percent) for the whole sample period (row "All") and for non-overlapping five minute subsamples (rows " 5 " to "60"), where " 5 " denotes the first five minutes of the trading sessions, "10" denotes minutes five to ten of the trading sessions and so on. Columns two to five show moments of the return distribution and first order midquote return autocorrelation coefficients $\left(\rho_{-1}\right)$. "Trade size" denotes the average size of a market order in USD and "Number of trades" shows the number of market orders for a given sample. The last column shows the quoted percentage spread in a given interval. 
Table 2

Descriptive statistics for order submissions and trader groups

\begin{tabular}{|c|c|c|c|c|}
\hline & $\begin{array}{c}\text { All } \\
\text { traders }\end{array}$ & $\begin{array}{l}\text { Large } \\
\text { traders }\end{array}$ & $\begin{array}{l}\text { Medium-sized } \\
\text { traders }\end{array}$ & $\begin{array}{c}\text { Small } \\
\text { Traders }\end{array}$ \\
\hline Market order vol. & 697 & 116 & 438 & 138 \\
\hline Market order obs. & 14,109 & 1,993 & 6,826 & 5,290 \\
\hline Limit order vol. & 1,633 & 265 & 973 & 395 \\
\hline Limit order obs. & 15,959 & 882 & 5,831 & 9,246 \\
\hline $\begin{array}{l}\text { Market orders } \\
\text { (vol. per trader) }\end{array}$ & 0.97 & 5.52 & 2.86 & 0.25 \\
\hline $\begin{array}{l}\text { Market orders } \\
\text { (obs. per trader) }\end{array}$ & 19.54 & 94.9 & 44.04 & 9.69 \\
\hline $\begin{array}{l}\text { Market orders } \\
\text { (vol. per order) }\end{array}$ & 0.049 & 0.058 & 0.064 & 0.026 \\
\hline $\begin{array}{l}\text { Limit orders } \\
\text { (vol. per trader) }\end{array}$ & 2.26 & 12.62 & 6.28 & 0.72 \\
\hline $\begin{array}{l}\text { Limit orders } \\
\text { (obs. per trader) }\end{array}$ & 22.10 & 42.00 & 37.62 & 16.93 \\
\hline $\begin{array}{l}\text { Limit orders } \\
\text { (vol. per order) }\end{array}$ & 0.102 & 0.300 & 0.167 & 0.043 \\
\hline No. of traders & 722 & 21 & 155 & 546 \\
\hline
\end{tabular}

This table presents descriptive statistics for traders in our sample. The upper part of the table shows aggregate volume (in million USD) and the number of market and limit orders. The middle part shows statistics for market orders per trader and per order (in million USD for volume figures) while the lower part shows the same for limit orders. Numbers are for all traders jointly, or for large, medium-sized, and small traders. 


\section{Table 3}

All traders: Private and public order flow

\begin{tabular}{|c|c|c|c|c|}
\hline & (i) & (ii) & (iii) & (iv) \\
\hline $\operatorname{LOOF}\left(\beta_{1}\right)$ & $\begin{array}{r}0.211 \\
* * *[2.99]\end{array}$ & & $\begin{array}{r}0.288 \\
* * *[3.67]\end{array}$ & $\begin{array}{r}0.257 \\
* * *[4.51]\end{array}$ \\
\hline LOOF $\times \operatorname{size}\left(\beta_{2}\right)$ & & & $\begin{array}{r}-0.191 \\
* * *[-5.29]\end{array}$ & $\begin{array}{r}-0.173 \\
* * *[-5.75]\end{array}$ \\
\hline Lagged oflow $(\gamma)$ & & $\begin{array}{r}0.101 \\
* * *[3.13]\end{array}$ & & $\begin{array}{r}0.139 \\
* * *[2.76]\end{array}$ \\
\hline Lagged returns $(\delta)$ & & $\begin{array}{r}0.024 \\
{[0.55]}\end{array}$ & & $\begin{array}{r}0.011 \\
{[1.12]}\end{array}$ \\
\hline Const. $(\alpha)$ & $\begin{array}{r}0.074 \\
* *[2.22] \\
\end{array}$ & $\begin{array}{r}0.079 \\
* * *[5.01] \\
\end{array}$ & $\begin{array}{r}0.080 \\
* *[2.12] \\
\end{array}$ & $\begin{array}{r}0.069 \\
* *[1.96] \\
\end{array}$ \\
\hline$R^{2}$ & 0.11 & 0.09 & 0.16 & 0.16 \\
\hline$\tau$ & 0.30 & 0.35 & 0.32 & 0.21 \\
\hline$\rho(u, \mu)$ & 0.25 & 0.09 & 0.18 & 0.28 \\
\hline Obs & 9,688 & 9,688 & 9,688 & 9,688 \\
\hline
\end{tabular}

This table shows results for fixed-effects panel regressions of the form

$$
\mathrm{x}_{\mathrm{k}}^{\mathrm{i}}=\alpha^{\mathrm{i}}+\beta_{1} \mathrm{x}_{[\mathrm{k}-1]}^{\mathrm{i}}+\beta_{2} \mathrm{x}_{[\mathrm{k}-1]}^{\mathrm{i}} \cdot \lambda_{[\mathrm{k}-1]}^{\mathrm{i}, \mathrm{C}}+\gamma \mathrm{x}_{\mathrm{k}-1 ; \mathrm{t}}^{\mathrm{A}}+\delta \mathrm{r}_{\mathrm{k}-1}+\xi_{\mathrm{k}}
$$

where market order flow by trader $i$ at time $k$ (denoted as $\mathrm{x}_{\mathrm{k}}$ ) is regressed on the last own order flow of trader $i$ on his own last order flow $\left(\mathrm{x}_{[\mathrm{k}-1]}\right)$ which we denote "LOOF" in the table below, on his last own order flow interacted with the trader size $\lambda_{[\mathrm{k}-1]}^{\mathrm{C}}$ of the last counterparty ("LOOF $\times$ size"), on lagged, aggregate market order flow $x_{[k-1]}^{A}$ ("Lagged oflow"), and on lagged midquote returns $r_{\mathrm{k}-1}$ ("Lagged returns"). $\tau$ denotes the fraction of variance due to individual fixed-effects,$\rho(u, \mu)$ denotes correlation of the fixed-effects and conditional means. Stars refer to the level of significance: $* * *: \leq 0.01, * *: \leq 0.05, *: \leq 0.10$. 


\section{Table 4}

Different trader groups: Private and public order flow

\begin{tabular}{lrrr}
\hline & \multicolumn{1}{c}{$\begin{array}{c}\text { Large } \\
\text { traders }\end{array}$} & $\begin{array}{c}\text { Medium-sized } \\
\text { traders }\end{array}$ & \multicolumn{2}{c}{$\begin{array}{c}\text { Small } \\
\text { traders }\end{array}$} \\
\hline LOOF $\left(\beta_{1}\right)$ & 0.210 & 0.333 & 0.742 \\
& $* * *[3.61]$ & $* * *[4.23]$ & $* * *[7.35]$ \\
LOOF $\times$ size $\left(\beta_{2}\right)$ & -0.101 & -0.545 & -0.698 \\
& $*[-1.89]$ & $* * *[-2.71]$ & $* * *[-3.76]$ \\
Lagged oflow $(\gamma)$ & 0.449 & 0.401 & 0.079 \\
& $* * *[6.12]$ & $* * *[3.12]$ & $*[1.74]$ \\
Lagged returns $(\delta)$ & 0.431 & 0.124 & 0.011 \\
& $* *[2.11]$ & $*[1.89]$ & {$[0.78]$} \\
Const. $(\alpha)$ & 0.342 & 0.181 & -0.050 \\
& $*[1.74]$ & {$[1.65]$} & {$[-1.19]$} \\
\hline$R^{2}$ & 0.16 & 0.15 & 0.12 \\
$\tau$ & & & 0.46 \\
$\rho(\mathrm{u}, \mu)$ & 0.36 & 0.35 & 0.39 \\
Obs & & & 3,569 \\
& 0.32 & 0.30 & \\
\hline
\end{tabular}

This table shows results from the same regression specification underlying Table 3

$$
\mathrm{x}_{\mathrm{k}}^{\mathrm{i}}=\alpha^{\mathrm{i}}+\beta_{1} \mathrm{x}_{[\mathrm{k}-1]}^{\mathrm{i}}+\beta_{2} \mathrm{x}_{[\mathrm{k}-1]}^{\mathrm{i}} \cdot \lambda_{[\mathrm{k}-1]}^{\mathrm{i}, \mathrm{C}}+\gamma \mathrm{x}_{\mathrm{k}-1 ; \mathrm{t}}^{\mathrm{A}}+\delta \mathrm{r}_{\mathrm{k}-1}+\xi_{\mathrm{k}}
$$

where market order flow by trader $i$ at time $k$ (denoted as $\mathrm{x}$ ) is regressed on the last own order flow of trader $i$ on his own last order flow $\left(\mathrm{x}_{[\mathrm{k}-1]}\right.$, ) which we denote "LOOF" in the table below, on his last own order flow interacted with the trader size $\lambda$ of the last counterparty ("LOOF $\times$ size"), on lagged, aggregate market order flow $x_{[k-1]}^{A}$ ("Lagged oflow"), and on lagged midquote returns $r_{\mathrm{k}-1}$ ("Lagged returns"). However, here we estimate this regression separately for three different groups of traders. Traders are grouped by size, where size is proxied for by total trading volume. $\tau$ denotes the fraction of variance due to individual fixedeffects, $\rho(u, \mu)$ denotes correlation of the fixed-effects and conditional means. Stars refer to the level of significance: $* * *: \leq 0.01, * *: \leq 0.05, *: \leq 0.10$. 


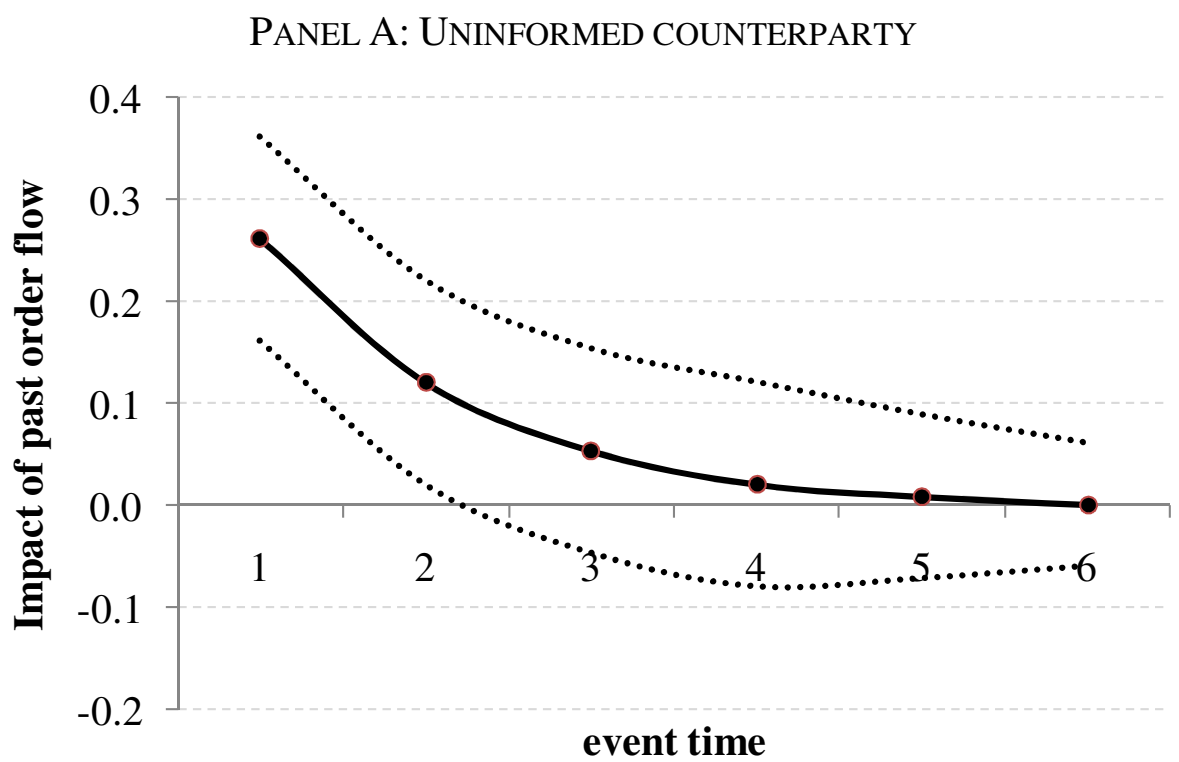

PANEL B: INFORMED COUNTERPARTY

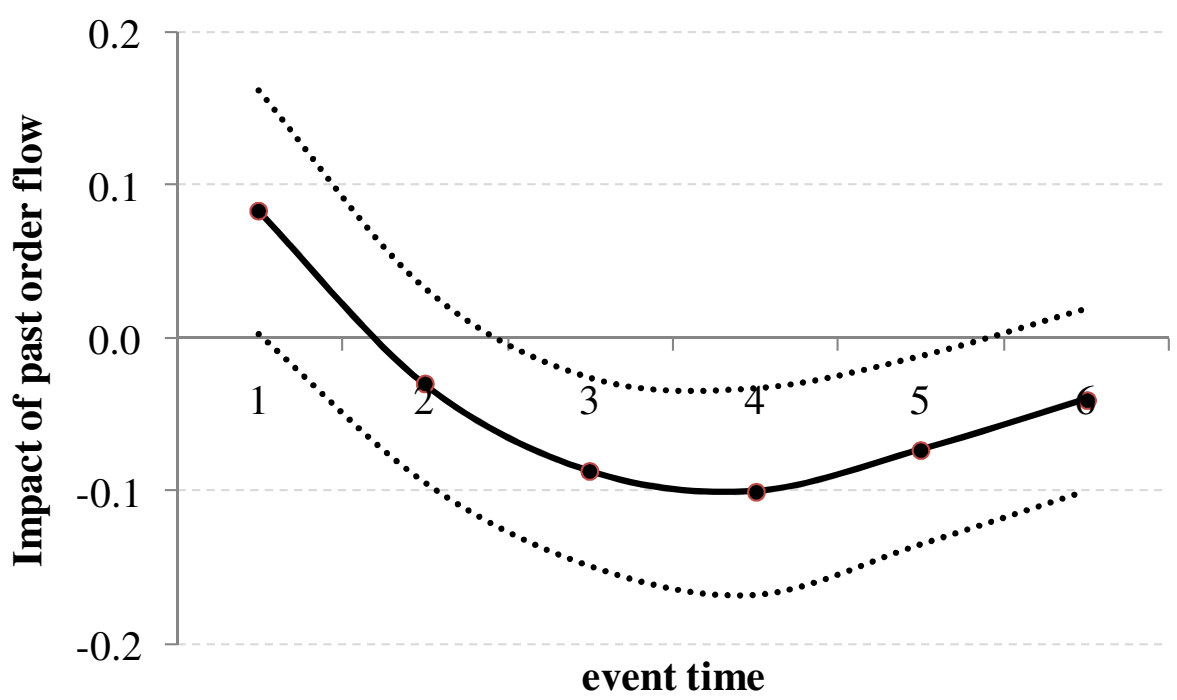

Fig. 1. This figure shows responses of future order flows (in event time) to earlier order flows. Panel A shows the evolution of a trader's order flow following an own buy order with an uninformed trader as last counterparty. Panel B shows the same for a buy order with an informed trader as last counterparty. The horizontal axis measures the number of trades after the initial transaction, whereas the vertical axis shows order flow decisions (volumes, divided by 100,000 USD). A positive value means that a trader is buying and vice versa. 


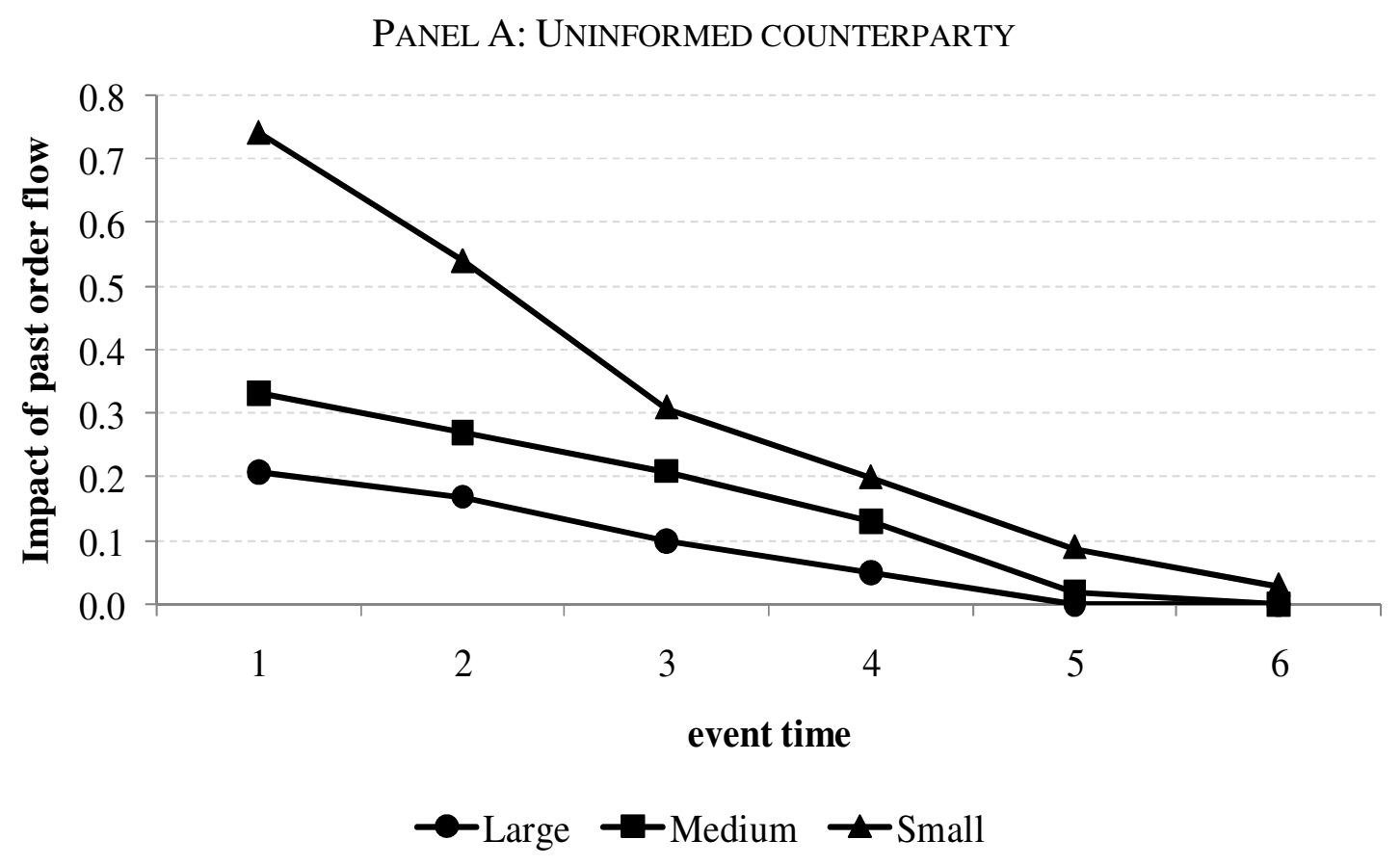

PANEL B: INFORMED COUNTERPARTY

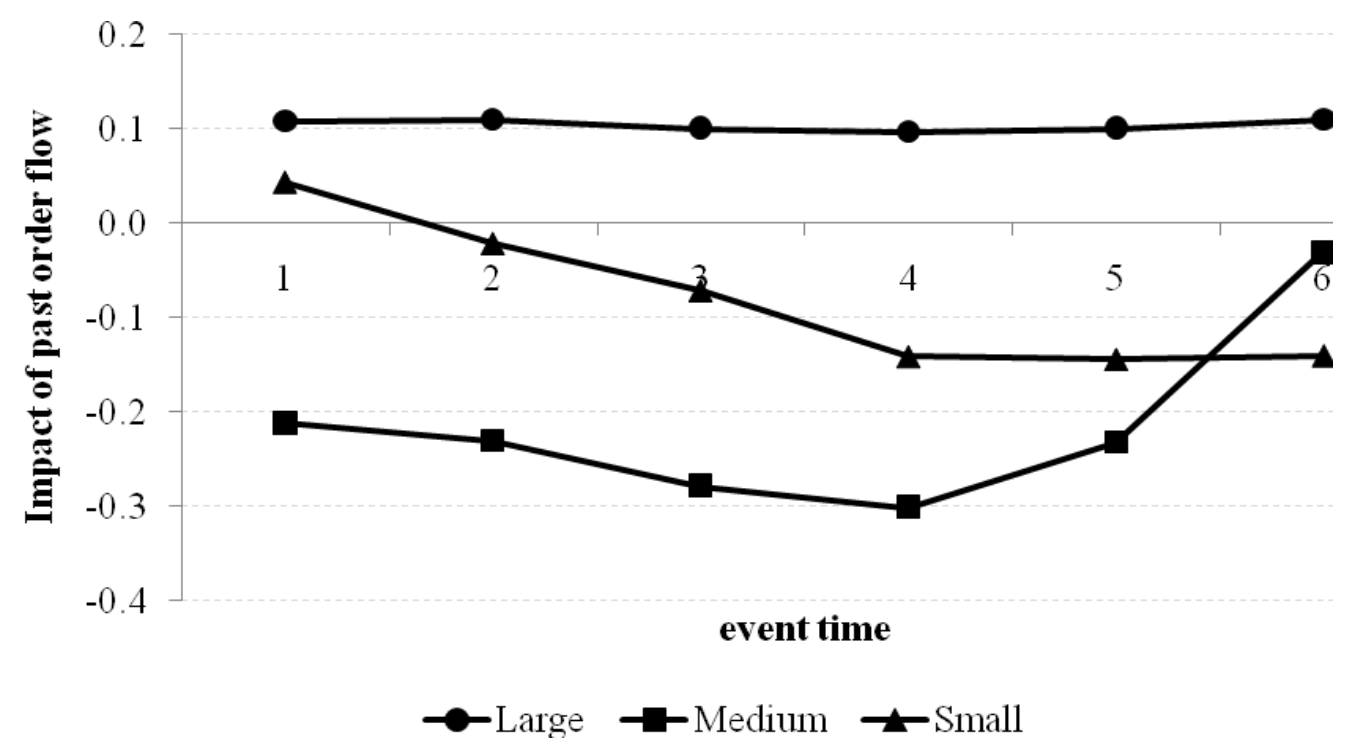

Fig. 2. This figure shows responses of future order flows (in event time) to earlier order flows for different trader groups (large, medium, and small traders). Panel A shows the evolution of a trader group's order flow following an own buy order with an uninformed trader as last counterparty. Panel B shows the same for a buy order with an informed trader as last counterparty. The horizontal axis measures the number of trades after the initial transaction, whereas the vertical axis shows order flow decisions (volumes, divided by 100,000 USD). A positive value means that a trader is buying and vice versa. 
Table 5

Controlling for order size

\begin{tabular}{lrrrr}
\hline & \multicolumn{1}{c}{$\begin{array}{c}\text { All } \\
\text { traders }\end{array}$} & \multicolumn{1}{c}{$\begin{array}{c}\text { Large } \\
\text { traders }\end{array}$} & $\begin{array}{c}\text { Medium-sized } \\
\text { traders }\end{array}$ & $\begin{array}{c}\text { Small } \\
\text { traders }\end{array}$ \\
\hline LOOF $\left(\beta_{1}\right)$ & 0.274 & 0.221 & 0.342 & 0.718 \\
& $* * *[4.20]$ & $* * *[3.72]$ & $* * *[4.55]$ & $* * *[7.29]$ \\
LOOF $\times$ lorder sizel $\left(\beta_{2}\right)$ & -0.043 & -0.033 & -0.075 & -0.101 \\
& {$[1.58]$} & {$[1.32]$} & $*[-1.79]$ & $* *[1.99]$ \\
LOOF $\times$ size $\left(\beta_{3}\right)$ & -0.178 & -0.098 & -0.578 & -0.616 \\
& $* * *[-4.96]$ & $*[-1.79]$ & $* * *[-2.93]$ & $* * *[-3.46]$ \\
Lagged oflow $(\gamma)$ & 0.044 & 0.460 & 0.375 & 0.072 \\
& $* * *[2.59]$ & $* * *[5.97]$ & $* * *[3.04]$ & {$[1.61]$} \\
Lagged returns $(\delta)$ & 0.013 & 0.429 & 0.119 & 0.008 \\
& {$[1.32]$} & $* *[2.13]$ & $*[1.72]$ & {$[0.57]$} \\
Const. $(\alpha)$ & 0.070 & 0.342 & 0.181 & -0.051 \\
& $* *[1.96]$ & $*[1.75]$ & {$[1.66]$} & {$[-1.32]$} \\
\hline$R^{2}$ & 0.16 & 0.16 & 0.15 & 0.13 \\
$\tau$ & & & & 0.47 \\
& 0.22 & 0.36 & 0.34 & 0.39 \\
Obs & & & & 3,569 \\
\hline
\end{tabular}

This table reports regression results for the specification

$$
\mathrm{x}_{\mathrm{k}}^{\mathrm{i}}=\alpha^{\mathrm{i}}+\beta_{1} \mathrm{x}_{[\mathrm{k}-1]}^{\mathrm{i}}+\beta_{2} \mathrm{x}_{[\mathrm{k}-1]}^{\mathrm{i}} \cdot\left|\mathrm{x}_{[\mathrm{k}-1]}^{\mathrm{i}}\right|+\beta_{3} \mathrm{x}_{[\mathrm{k}-1]}^{\mathrm{i}} \cdot \lambda_{[\mathrm{k}-1]}^{\mathrm{i}, \mathrm{C}}+\gamma \mathrm{x}_{\mathrm{k}-1 ; \mathrm{t}}^{\mathrm{A}}+\delta \mathrm{r}_{\mathrm{k}-1}+\xi_{\mathrm{k}}
$$

which is similar to the setup in the previous tables 3 and 4 but where we include an additional interaction term of a trader's last own order flow with the absolute dollar size of the last order $\left|\mathrm{x}_{[\mathrm{k}-1]}\right|$. $\tau$ denotes the fraction of variance due to individual fixed-effects, $\rho(\mathrm{u}, \mu)$ denotes correlation of the fixed-effects and conditional means. Stars refer to the level of significance: $* * *$ : $\leq 0.01, * *: \leq 0.05, *: \leq 0.10$. 
Table 6

Private versus public information

\begin{tabular}{lrrrr}
\hline & \multicolumn{1}{c}{$\begin{array}{c}\text { All } \\
\text { traders }\end{array}$} & \multicolumn{1}{c}{$\begin{array}{c}\text { Large } \\
\text { traders }\end{array}$} & $\begin{array}{c}\text { Medium-sized } \\
\text { traders }\end{array}$ & $\begin{array}{c}\text { Small } \\
\text { traders }\end{array}$ \\
\hline LOOF $\left(\beta_{1}\right)$ & 0.251 & 0.228 & 0.299 & 0.713 \\
& $* * *[4.27]$ & $* * *[3.89]$ & $* * *[4.02]$ & $* * *[6.79]$ \\
LOOF $\times$ size $\left(\beta_{2}\right)$ & -0.180 & -0.121 & -0.561 & -0.700 \\
& $* * *[-5.79]$ & $*[-1.73]$ & $* * *[-2.88]$ & $* * *[-3.86]$ \\
Lagged oflow $\left(\gamma_{1}\right)$ & 0.184 & 0.447 & 0.365 & 0.113 \\
& $* * *[2.71]$ & $* * *[6.05]$ & $* * *[3.13]$ & $*[1.96]$ \\
Lagged oflow $\times$ size $\left(\gamma_{2}\right)$ & -0.042 & -0.026 & -0.071 & -0.038 \\
& $* *[-1.99]$ & {$[-0.71]$} & $* *[-2.48]$ & $*[-1.95]$ \\
Lagged returns $(\delta)$ & 0.014 & 0.410 & 0.098 & 0.003 \\
& {$[1.03]$} & $*[2.09]$ & {$[1.32]$} & {$[0.69]$} \\
Const. $(\alpha)$ & 0.074 & 0.342 & 0.180 & -0.051 \\
& $* *[2.21]$ & $*[1.75]$ & {$[1.66]$} & {$[-1.19]$} \\
\hline$R^{2}$ & 0.16 & 0.16 & 0.17 & 0.13 \\
$\tau$ & & & & 0.46 \\
& 0.20 & 0.36 & 0.33 & 0.39 \\
Obs & & & & 3,569 \\
\hline
\end{tabular}

This table reports regression results of traders' market order flow at time $k$ (denoted $\mathrm{x}_{\mathrm{k}}$ ) on their last own order flow (LOOF, $\left.\mathrm{x}_{[\mathrm{k}-1]}\right)$, lagged aggregate market order flow $\left(\mathrm{x}_{[\mathrm{k}-1]}^{\mathrm{A}}\right)$, the last two variables interacted with the size of the respective last counterparty $\left(\lambda_{[\mathrm{k}-1]}^{\mathrm{C}}\right)$ and lagged returns $\left(\mathrm{r}_{[\mathrm{k}-1]}\right)$ :

$$
\mathrm{x}_{\mathrm{k}}^{\mathrm{i}}=\alpha^{\mathrm{i}}+\beta_{1} \mathrm{x}_{[\mathrm{k}-1]}^{\mathrm{i}}+\beta_{2} \mathrm{x}_{[\mathrm{k}-1]}^{\mathrm{i}} \cdot \lambda_{[\mathrm{k}-1]}^{\mathrm{i}, \mathrm{C}}+\gamma_{1} \mathrm{x}_{\mathrm{k}-1 ; \mathrm{t}}^{\mathrm{A}}+\gamma_{2} \mathrm{x}_{\mathrm{k}-1 ; \mathrm{t}}^{\mathrm{A}} \cdot \lambda_{[\mathrm{k}-1]}^{\mathrm{i}, \mathrm{C}}+\delta \mathrm{r}_{\mathrm{k}-1}+\xi_{\mathrm{k}} .
$$

$\tau$ denotes the fraction of variance due to individual fixed-effects, $\rho(u, \mu)$ denotes correlation of the fixed-effects and conditional means. Stars refer to the level of significance: $* * *: \leq 0.01$, $* *: \leq 0.05, *: \leq 0.10$. 
Table 7

Order flow sources

\begin{tabular}{lrrrr}
\hline & \multicolumn{1}{c}{$\begin{array}{c}\text { All } \\
\text { traders }\end{array}$} & \multicolumn{1}{c}{$\begin{array}{c}\text { Large } \\
\text { traders }\end{array}$} & $\begin{array}{c}\text { Medium-sized } \\
\text { traders }\end{array}$ & $\begin{array}{c}\text { Small } \\
\text { traders }\end{array}$ \\
\hline LOOF, market & 0.391 & 0.217 & 0.378 & 0.643 \\
& $* * *[5.99]$ & $* * *[3.44]$ & $* * *[4.23]$ & $* * *[4.09]$ \\
LOOF, limit & 0.195 & 0.132 & 0.201 & 0.232 \\
& $* *[2.52]$ & $* *[2.12]$ & $* *[2.31]$ & $* *[2.44]$ \\
LOOF, market $\times$ size & -0.139 & -0.093 & -0.145 & -0.164 \\
& $* *[-2.14]$ & $* *[-1.99]$ & $* *[-2.03]$ & $* *[-2.50]$ \\
LOOF, limit $\times$ size & -0.181 & -0.110 & -0.164 & -0.276 \\
& $* * *[-4.56]$ & $* *[-2.32]$ & $* *[-2.49]$ & $* * *[-3.08]$ \\
Lagged oflow & 0.050 & 0.402 & 0.371 & 0.042 \\
& $* * *[3.01]$ & $* * *[3.76]$ & $* *[2.05]$ & {$[0.87]$} \\
Lagged returns & 0.019 & 0.387 & 0.109 & 0.009 \\
Const. & $*[1.79]$ & $* *[2.15]$ & $*[1.97]$ & {$[0.54]$} \\
& 0.054 & 0.341 & 0.092 & -0.067 \\
\hline$R^{2}$ & $*[1.72]$ & $* *[2.43]$ & $*[1.96]$ & {$[-0.98]$} \\
$\tau$ & 0.15 & 0.17 & 0.14 & 0.13 \\
& & & & 0.33 \\
$\rho(\mathrm{u}, \mu)$ & 0.31 & 0.34 & 0.32 & \\
Obs. & & & & 0.38 \\
\hline
\end{tabular}

The setup of this table is identical to that in Tables 3 and 4 but here we separate last own order flows stemming from market and limit orders ("LOOF, market" and "LOOF, limit") and we also separately interact last own order flows from market and limit orders with the size of the last counterparty ("LOOF, market $\times$ size" and "LOOF, limit $\times$ size"). We refer to Tables 3 and 4 for further details. $\tau$ denotes the fraction of variance due to individual fixed-effects, $\rho(u, \mu)$ denotes correlation of the fixed-effects and conditional means. Stars refer to the level of significance: $* * *: \leq 0.01, * *: \leq 0.05, *: \leq 0.10$. 
Table 8

Using pre-sample information to classify traders

\begin{tabular}{|c|c|c|c|c|}
\hline & \multicolumn{2}{|c|}{ Based on earlier period } & \multicolumn{2}{|c|}{ Second half of original sample } \\
\hline & (i) & (ii) & (i) & (ii) \\
\hline $\operatorname{LOOF}\left(\beta_{1}\right)$ & $\begin{array}{r}0.297 \\
* * *[2.91]\end{array}$ & $\begin{array}{r}0.266 \\
* * *[3.07]\end{array}$ & $\begin{array}{r}0.334 \\
* *[2.04]\end{array}$ & $\begin{array}{r}0.300 \\
* *[2.49]\end{array}$ \\
\hline LOOF $\times \operatorname{size}\left(\beta_{2}\right)$ & $\begin{array}{r}-0.132 \\
* * *[-4.10]\end{array}$ & $\begin{array}{r}-0.154 \\
* * *[-4.44]\end{array}$ & $\begin{array}{r}-0.224 \\
* *[-2.45]\end{array}$ & $\begin{array}{r}-0.195 \\
* *[-2.30]\end{array}$ \\
\hline Lagged oflow $(\gamma)$ & & $\begin{array}{r}0.136 \\
* * *[2.77]\end{array}$ & & $\begin{array}{r}0.110 \\
* *[1.98]\end{array}$ \\
\hline Lagged returns $(\delta)$ & & $\begin{array}{r}0.010 \\
{[1.01]}\end{array}$ & & $\begin{array}{r}0.023 \\
{[1.41]}\end{array}$ \\
\hline Const. $(\alpha)$ & $\begin{array}{r}0.077 \\
* *[2.23]\end{array}$ & $\begin{array}{r}0.070 \\
*[1.94]\end{array}$ & $\begin{array}{r}0.076 \\
*[1.91]\end{array}$ & $\begin{array}{r}0.079 \\
* *[1.99]\end{array}$ \\
\hline$R^{2}$ & 0.14 & 0.15 & 0.09 & 0.11 \\
\hline$\tau$ & 0.29 & 0.33 & 0.28 & 0.20 \\
\hline$\rho(u, \mu)$ & 0.26 & 0.25 & 0.22 & 0.21 \\
\hline Obs & 7,632 & 7,632 & 4,213 & 4,213 \\
\hline
\end{tabular}

The setup of this table is identical to Table 3, specifications (iii) and (iv), but here we estimate the size of a trader by either relying on pre-sample information based on an earlier period from March 1 to March 7 (left part of the table) or on splitting our original sample in two halfs. In the latter case we measure trader size by a trader's total trading volume from March 11 to March 15 and then estimate our model on the remaining sample from March 18 to March 22 (shown in the right part of this table). Note that we lose observations in both cases since we do not have information for all traders (smaller traders with few observations) in the earlier period or the first half of the original sample period. The correlation of our original trader size measure with the size based on the earlier period is 0.87 whereas the correlation with the measure based on the first half of the original period is 0.74 . Stars refer to the level of significance: $* * *: \leq 0.01, * *: \leq 0.05, *: \leq 0.10$ and the definitions of Table 3 apply for the remaining parts of the table. 
Supplementary Appendix to accompany

Trader see, trader do: How do (small) FX traders react to large counterparties' trades? 
PANEL A: LARGE TRADERS

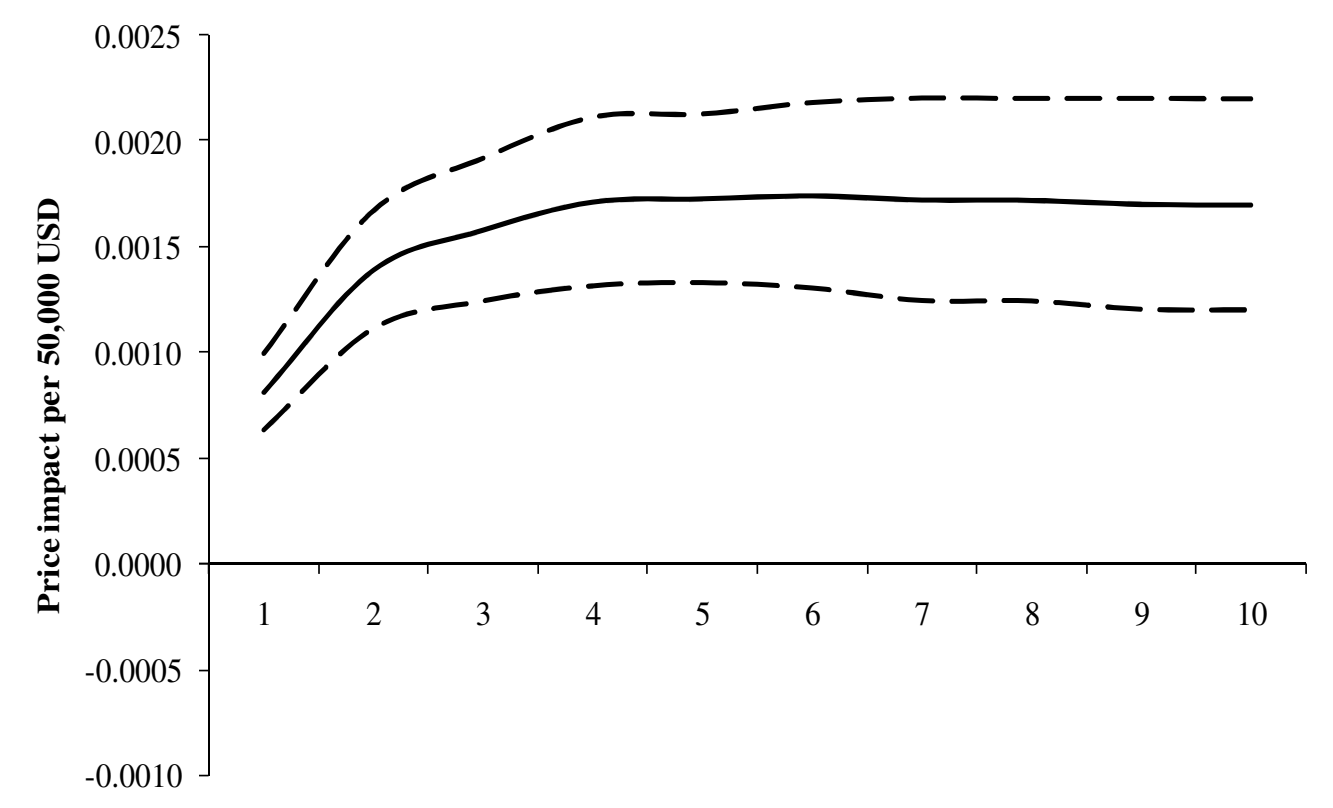

PANEL B: SMALL TRADERS

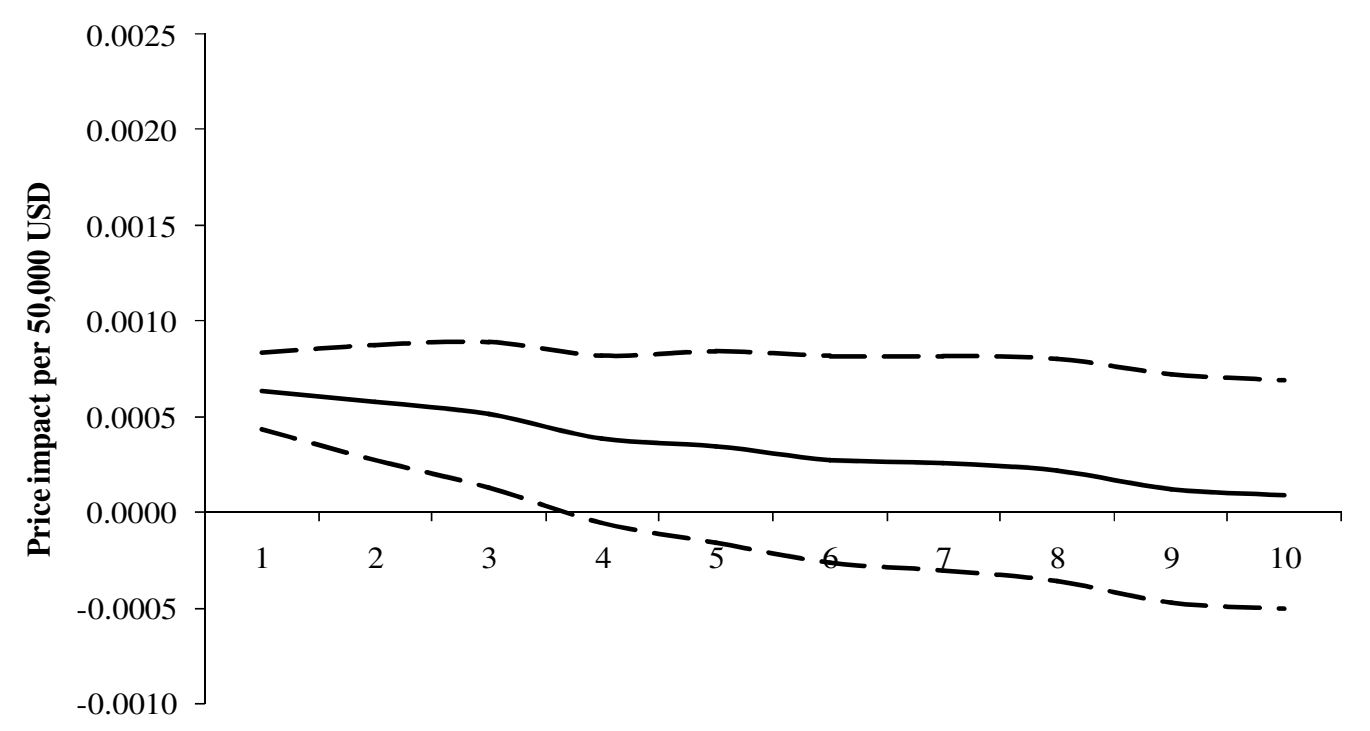

Fig. A.1. This figure shows the price impact of order flow resulting from large (Panel A) and small traders (Panel B) over time. Results are based on a VAR (one lag) with midquote returns, order flow of large traders and order flow of small traders as endogenous variables. Price impacts are cumulative and computed as generalized impulse-responses of midquote returns to order flow shocks. The shock size is equivalent to a 50,000 USD trade for both large and small traders. We use a sampling frequency of 30 seconds so that cumulative price impacts are shown over 5 minutes. The total price impact of $0.0017 \%$ for large traders translates into a price impact of about 5.5 pips in a market that has an average bid-ask spread of 17 pips. 
Table A.1

Impact of trade durations

\begin{tabular}{|c|c|c|c|c|}
\hline & $\begin{array}{c}\text { All } \\
\text { traders }\end{array}$ & $\begin{array}{l}\text { Large } \\
\text { traders }\end{array}$ & $\begin{array}{l}\text { Medium-sized } \\
\text { traders }\end{array}$ & $\begin{array}{l}\text { Small } \\
\text { traders }\end{array}$ \\
\hline \multirow[t]{2}{*}{$\operatorname{LOOF}\left(\beta_{1}\right)$} & 0.264 & 0.198 & 0.307 & 0.731 \\
\hline & $* * *[4.75]$ & $* * *[3.34]$ & $* * *[3.96]$ & $* * *[7.29]$ \\
\hline \multirow[t]{2}{*}{ LOOF $\times$ duration $\left(\beta_{2}\right)$} & -0.001 & 0.004 & -0.031 & -0.000 \\
\hline & {$[-0.00]$} & {$[0.72]$} & {$[-1.01]$} & {$[-0.03]$} \\
\hline \multirow[t]{2}{*}{ LOOF $\times \operatorname{size}\left(\beta_{3}\right)$} & -0.189 & -0.116 & -0.511 & -0.714 \\
\hline & $* * *[-5.85]$ & $* *[2.03]$ & $* * *[-2.54]$ & $* * *[-3.49]$ \\
\hline \multirow[t]{2}{*}{ LOOF $\times$ size $\times$ duration $\left(\beta_{4}\right)$} & 0.076 & 0.045 & 0.112 & 0.093 \\
\hline & $* *[2.31]$ & {$[0.86]$} & $*[1.75]$ & $* *[2.21]$ \\
\hline \multirow[t]{2}{*}{ Lagged oflow $(\gamma)$} & 0.038 & 0.460 & 0.412 & 0.074 \\
\hline & $* * *[2.69]$ & $* * *[6.51]$ & $* * *[2.89]$ & [1.63] \\
\hline \multirow[t]{2}{*}{ Lagged returns $(\delta)$} & 0.010 & 0.318 & 0.121 & 0.008 \\
\hline & {$[1.27]$} & $* *[2.02]$ & $*[1.73]$ & {$[0.58]$} \\
\hline \multirow[t]{2}{*}{ Const. $(\alpha)$} & 0.069 & 0.342 & 0.180 & -0.051 \\
\hline & $* *[1.98]$ & $*[1.69]$ & [1.63] & {$[1.20]$} \\
\hline$R^{2}$ & 0.16 & 0.16 & 0.15 & 0.13 \\
\hline$\tau$ & 0.20 & 0.35 & 0.35 & 0.44 \\
\hline$\rho(u, \mu)$ & 0.29 & 0.32 & 0.29 & 0.39 \\
\hline Obs & 9,688 & 1,798 & 4,321 & 3,569 \\
\hline
\end{tabular}

This table reports results for the regression

$$
\begin{aligned}
\mathrm{x}_{\mathrm{k}}^{\mathrm{i}}=\alpha^{\mathrm{i}} & +\beta_{1} \mathrm{x}_{[\mathrm{k}-1]}^{\mathrm{i}}+\beta_{2} \mathrm{x}_{[\mathrm{k}-1]}^{\mathrm{i}} \cdot \mathrm{d}_{[\mathrm{k}-1]}^{\mathrm{i}} \\
& +\beta_{3} \mathrm{x}_{[\mathrm{k}-1]}^{\mathrm{i}} \cdot \lambda_{[\mathrm{k}-1]}^{\mathrm{i}, \mathrm{C}}+\beta_{4} \mathrm{x}_{[\mathrm{k}-1]}^{\mathrm{i}} \cdot \lambda_{[\mathrm{k}-1]}^{\mathrm{i}, \mathrm{C}} \cdot \mathrm{d}_{[\mathrm{k}-1]}^{\mathrm{i}} \\
& +\gamma_{1} \mathrm{x}_{\mathrm{k}-1 ; \mathrm{t}}^{\mathrm{A}}+\gamma_{2} \mathrm{x}_{\mathrm{k}-1 ; \mathrm{t}}^{\mathrm{A}} \cdot \lambda_{[\mathrm{k}-1]}^{\mathrm{i}, \mathrm{C}}+\delta \mathrm{r}_{\mathrm{k}-1}+\xi_{\mathrm{k}}
\end{aligned}
$$

of traders' market order flow $\left(\mathrm{x}_{\mathrm{k}}\right)$ on their last own order flow $\left(\mathrm{x}_{[\mathrm{k}-1]}\right.$, denoted LOOF in the Table below), the same variables interacted with the duration since the last own trade $\mathrm{d}_{[\mathrm{k}-\mathrm{A}]}$, the size of the respective last counterparty $\lambda_{[\mathrm{k}-1]}^{\mathrm{C}}$, lagged aggregate market order flow $\left(\mathrm{x}_{\mathrm{k}-1}^{\mathrm{A}}\right)$ and lagged returns $\left(\mathrm{r}_{\mathrm{k}-1}\right) . \tau$ denotes the fraction of variance due to individual fixed-effects, $\rho(u, \mu)$ denotes correlation of the fixed-effects and conditional means. Stars refer to the level of significance: $* * *: \leq 0.01, * *: \leq 0.05, *: \leq 0.10$. 
Table A.2

Cumulative order flows

\begin{tabular}{lrrrr}
\hline & \multicolumn{1}{c}{$\begin{array}{c}\text { All } \\
\text { traders }\end{array}$} & \multicolumn{1}{c}{$\begin{array}{c}\text { Large } \\
\text { traders }\end{array}$} & $\begin{array}{c}\text { Medium-sized } \\
\text { traders }\end{array}$ & \multicolumn{1}{c}{$\begin{array}{c}\text { Small } \\
\text { Traders }\end{array}$} \\
\hline LOOF cum & 0.231 & 0.187 & 0.289 & 0.305 \\
& $* *[2.07]$ & $* *[1.97]$ & $* *[2.37]$ & $* *[2.54]$ \\
LOOF cum $\times$ size & -0.174 & -0.132 & -0.191 & -0.287 \\
& $* * *[-3.37]$ & $* *[2.30]$ & $* *[-2.18]$ & $* * *[-3.48]$ \\
Lagged oflow & 0.043 & 0.301 & 0.121 & 0.051 \\
& $* * *[2.78]$ & $* *[2.61]$ & $*[1.87]$ & {$[1.25]$} \\
Lagged returns & 0.014 & 0.214 & 0.083 & 0.007 \\
Const. & {$[1.12]$} & $* *[1.98]$ & {$[1.61]$} & {$[0.83]$} \\
& 0.058 & 0.212 & 0.104 & -0.081 \\
$R^{2}$ & $*[1.69]$ & $* *[2.01]$ & {$[1.34]$} & {$[-1.41]$} \\
$\tau$ & 0.16 & 0.18 & 0.16 & 0.17 \\
& & & & 0.31 \\
$\rho(\mathrm{u}, \mu)$ & 0.32 & 0.30 & 0.34 & 0.33 \\
Obs. & 0.29 & & & \\
& & 0.28 & 0.30 & 3,569 \\
\hline
\end{tabular}

The setup of this table is identical to tables 3 and 4 but here we use cumulative order flow instead of only the last own order flow of the previous day. The regression reads

$$
\mathrm{x}_{\mathrm{k}}^{\mathrm{i}}=\alpha^{\mathrm{i}}+\beta_{1} \tilde{\mathrm{x}}_{[\mathrm{k}-1]}^{\mathrm{i}}+\beta_{2} \theta_{[\mathrm{k}-1]}^{\mathrm{i}}+\gamma \mathrm{x}_{\mathrm{k}-1 ; \mathrm{t}}^{\mathrm{A}}+\delta \mathrm{r}_{\mathrm{k}-1}+\xi_{\mathrm{k}}
$$

where $\tilde{x}$ denotes cumulative order flow over the day (denoted "Loof cum" in the table) and $\theta$ denotes cumulative order flow weighted by the counterparty's size (denoted "Loof cum xsize" below). We refer to section 5 of the paper and tables 3 and 4 for further details. $\tau$ denotes the fraction of variance due to individual fixed-effects, $\rho(u, \mu)$ denotes correlation of the fixed-effects and conditional means. Stars refer to the level of significance: $* * *: \leq 0.01$, $* *: \leq 0.05, *: \leq 0.10$. 
Table A.3

Order flow indicators

\begin{tabular}{|c|c|c|c|c|}
\hline & $\begin{array}{c}\text { All } \\
\text { traders }\end{array}$ & $\begin{array}{l}\text { Large } \\
\text { traders }\end{array}$ & $\begin{array}{c}\text { Medium- } \\
\text { sized traders }\end{array}$ & $\begin{array}{c}\text { Small } \\
\text { Traders }\end{array}$ \\
\hline \multirow[t]{2}{*}{$\operatorname{LOOF}\left(\beta_{1}\right)$} & 1.624 & 0.986 & 1.591 & 1.797 \\
\hline & $* * *[5.22]$ & $* * *[5.99]$ & $* * *[5.48]$ & $* * *[6.90]$ \\
\hline \multirow[t]{2}{*}{ LOOF $\times \operatorname{size}\left(\beta_{2}\right)$} & -1.000 & -0.427 & -1.081 & -1.454 \\
\hline & $* * *[-6.93]$ & $* *[-2.01]$ & $* * *[-3.56]$ & $* * *[-3.38]$ \\
\hline \multirow[t]{2}{*}{ Lagged oflow $(\gamma)$} & 0.144 & 0.362 & 0.200 & 0.008 \\
\hline & $* * *[4.92]$ & $* * *[8.35]$ & $* *[2.44]$ & {$[0.85]$} \\
\hline \multirow[t]{2}{*}{ Lagged returns $(\delta)$} & 0.171 & 0.332 & 0.213 & 0.117 \\
\hline & $* * *[3.26]$ & $* * *[4.09]$ & $* *[2.28]$ & $*[1.77]$ \\
\hline \multirow[t]{2}{*}{ Const. $(\alpha)$} & 0.291 & 0.425 & 0.280 & 0.034 \\
\hline & $* * *[3.32]$ & $* *[2.43]$ & $*[1.76]$ & {$[0.65]$} \\
\hline Pseudo $-R^{2}$ & 0.101 & 0.112 & 0.097 & 0.072 \\
\hline Obs & 9,688 & 1,798 & 4,321 & 3,569 \\
\hline
\end{tabular}

The setup of this table is identical to that of Table 3 but here we employ order flow indicators (equal to one for a buyer-initiated order and equal to minus one for a seller-initiated order) instead of order flow volumes and specify a panel logit model

$$
\mathrm{P}\left(\mathrm{x}_{\mathrm{k}}^{\mathrm{i}} \geq 0\right)=\Lambda\left(\alpha^{\mathrm{i}}+\beta_{1} \mathrm{x}_{[\mathrm{k}-1]}^{\mathrm{Ind}, \mathrm{i}}+\beta_{2} \mathrm{x}_{[\mathrm{k}-1]}^{\mathrm{Ind}, \mathrm{i}} \cdot \lambda_{[\mathrm{k}-1]}^{\mathrm{i}, \mathrm{C}}+\gamma \mathrm{x}_{\mathrm{k}-1 ; \mathrm{t}}^{\mathrm{Ind}, \mathrm{A}}+\delta \mathrm{r}_{\mathrm{k}-1}\right)
$$

We use order flow indicators for the dependent variable, the lagged dependent variable (LOOF), as well as the lagged market-wide order flow control variable. We employ a panel logit model on the pooled sample of all traders. Stars refer to the level of significance: $* * *$ : $\leq 0.01, * *: \leq 0.05, *: \leq 0.10$. 
Table A.4

Time-of-the-day effects

\begin{tabular}{|c|c|c|c|c|}
\hline & $\begin{array}{c}\text { All } \\
\text { traders }\end{array}$ & $\begin{array}{l}\text { Large } \\
\text { traders }\end{array}$ & $\begin{array}{l}\text { Medium-sized } \\
\text { traders }\end{array}$ & $\begin{array}{l}\text { Small } \\
\text { traders }\end{array}$ \\
\hline \multirow{2}{*}{$\operatorname{LOOF}\left(\beta_{1}\right)$} & 0.249 & 0.211 & 0.330 & 0.758 \\
\hline & $* * *[4.38]$ & $* * *[3.60]$ & $* * *[3.94]$ & $* * *[7.01]$ \\
\hline \multirow[t]{2}{*}{ LOOF $\times \operatorname{size}\left(\beta_{2}\right)$} & -0.177 & -0.114 & -0.555 & -0.692 \\
\hline & $* * *[-5.76]$ & $* *[-1.99]$ & $* * *[-2.85]$ & $* * *[-3.48]$ \\
\hline \multirow[t]{2}{*}{ Lagged oflow $(\gamma)$} & 0.139 & 0.467 & 0.375 & 0.078 \\
\hline & $* * *[2.74]$ & $* * *[5.78]$ & $* * *[3.19]$ & $*[1.70]$ \\
\hline \multirow[t]{2}{*}{ Lagged returns $(\delta)$} & 0.014 & 0.434 & 0.108 & 0.009 \\
\hline & [1.19] & $* *[2.17]$ & $*[1.70]$ & {$[0.75]$} \\
\hline \multirow[t]{2}{*}{ Const. $(\alpha)$} & 0.067 & 0.308 & 0.172 & -0.061 \\
\hline & [1.22] & $*[1.86]$ & [1.67] & {$[-1.41]$} \\
\hline \multirow[t]{2}{*}{ Time $1-10\left(\phi_{1}\right)$} & -0.002 & 0.008 & -0.006 & 0.001 \\
\hline & {$[-0.14]$} & {$[0.82]$} & {$[-0.31]$} & {$[0.18]$} \\
\hline \multirow[t]{2}{*}{ Time $11-20\left(\phi_{2}\right)$} & 0.010 & 0.001 & 0.005 & 0.012 \\
\hline & {$[0.92]$} & [0.13] & {$[0.23]$} & {$[0.54]$} \\
\hline \multirow[t]{2}{*}{ Time $21-30\left(\phi_{3}\right)$} & 0.011 & -0.001 & 0.015 & 0.004 \\
\hline & [1.17] & {$[-0.02]$} & {$[1.01]$} & [0.03] \\
\hline \multirow[t]{2}{*}{ Time $31-40\left(\phi_{4}\right)$} & -0.009 & -0.003 & -0.007 & -0.010 \\
\hline & {$[-0.44]$} & {$[-0.39]$} & {$[-0.21]$} & {$[-0.41]$} \\
\hline \multirow{2}{*}{ Time $41-50\left(\phi_{5}\right)$} & 0.004 & 0.012 & -0.001 & -0.002 \\
\hline & {$[0.00]$} & {$[0.84]$} & {$[-0.00]$} & {$[-0.09]$} \\
\hline \multirow[t]{2}{*}{$\mathrm{F}\left(\right.$ all $\left.\phi_{\mathrm{i}}=0\right)$} & 1.014 & 1.390 & 0.872 & 0.695 \\
\hline & $(0.41)$ & $(0.23)$ & $(0.50)$ & $(0.63)$ \\
\hline$R^{2}$ & 0.16 & 0.16 & 0.15 & 0.12 \\
\hline$\tau$ & 0.20 & 0.33 & 0.33 & 0.46 \\
\hline$\rho(u, \mu)$ & 0.28 & 0.30 & 0.29 & 0.38 \\
\hline Obs & 9,688 & 1,798 & 4,321 & 3,569 \\
\hline
\end{tabular}

This table shows results from the same regression specification underlying Table 3

$$
\mathrm{x}_{\mathrm{k}}^{\mathrm{i}}=\alpha^{\mathrm{i}}+\beta_{1} \mathrm{x}_{[\mathrm{k}-1]}^{\mathrm{i}}+\beta_{2} \mathrm{x}_{[\mathrm{k}-1]}^{\mathrm{i}} \cdot \lambda_{[\mathrm{k}-1]}^{\mathrm{i}, \mathrm{C}}+\gamma \mathrm{x}_{\mathrm{k}-1 ; \mathrm{t}}^{\mathrm{A}}+\delta \mathrm{r}_{\mathrm{k}-1}+\phi^{\prime} \mathrm{time}_{\mathrm{k}}+\xi_{\mathrm{k}}
$$

but we additionally include a vector of five time dummies for the first five non-overlapping ten minutes intervals of each trading day (denoted "time"). We report the estimates for the five dummy variables and the test for joint significance (with corresponding p-values in parentheses). Stars refer to the level of significance: $* * *: \leq 0.01, * *: \leq 0.05, *: \leq 0.10$. 


\begin{tabular}{|c|c|c|c|c|c|c|}
\hline & \multicolumn{2}{|c|}{ Trading volume } & \multicolumn{2}{|c|}{ Bid-ask spread } & \multicolumn{2}{|c|}{ Return volatility } \\
\hline & High & Low & High & Low & High & Low \\
\hline \multirow{2}{*}{$\operatorname{LOOF}\left(\beta_{1}\right)$} & 0.326 & 0.167 & 0.101 & 0.323 & 0.212 & 0.301 \\
\hline & $* * *[2.98]$ & $* *[2.31]$ & $* *[2.03]$ & $* *[2.18]$ & $* *[2.14]$ & $* *[2.03]$ \\
\hline LOOF $\times$ size & -0.099 & -0.269 & -0.314 & -0.065 & -0.199 & -0.154 \\
\hline$\left(\beta_{2}\right)$ & $* *[-1.96]$ & $* * *[-3.56]$ & $* * *[-3.68]$ & $*[1.89]$ & $* *[2.47]$ & $* *[2.04]$ \\
\hline Lagged oflow & 0.032 & 0.043 & 0.046 & 0.022 & 0.040 & 0.035 \\
\hline$(\gamma)$ & $* *[2.07]$ & $* *[2.15]$ & $* *[2.09]$ & $*[1.91]$ & $* *[2.13]$ & $* *[1.98]$ \\
\hline Lagged returns & 0.007 & 0.016 & 0.019 & 0.008 & 0.014 & 0.010 \\
\hline$(\delta)$ & {$[0.56]$} & [1.44] & [1.57] & {$[0.83]$} & [1.39] & [1.07] \\
\hline \multirow[t]{2}{*}{ Const. $(\alpha)$} & 0.067 & 0.075 & 0.065 & 0.070 & 0.066 & 0.071 \\
\hline & $* *[1.97]$ & $* *[1.99]$ & $*[1.91]$ & $* *[2.03]$ & $*[1.92]$ & $* *[2.00]$ \\
\hline$R^{2}$ & 0.13 & 0.17 & 0.19 & 0.14 & 0.16 & 0.16 \\
\hline$\tau$ & 0.23 & 0.20 & 0.17 & 0.24 & 0.20 & 0.21 \\
\hline$\rho(u, \mu)$ & 0.30 & 0.23 & 0.24 & 0.32 & 0.26 & 0.28 \\
\hline Obs & 4,844 & 4,844 & 4,844 & 4,844 & 4,844 & 4,844 \\
\hline
\end{tabular}

This table provides results for the base regression in (1) but for different market states, namely times of high and low trading volume, bid-ask spreads, and return volatility. The regression specification

$$
\mathrm{x}_{\mathrm{k}}^{\mathrm{i}}=\alpha^{\mathrm{i}}+\beta_{1} \mathrm{x}_{[\mathrm{k}-1]}^{\mathrm{i}}+\beta_{2} \mathrm{x}_{[\mathrm{k}-1]}^{\mathrm{i}} \cdot \lambda_{[\mathrm{k}-1]}^{\mathrm{i}, \mathrm{C}}+\gamma \mathrm{x}_{\mathrm{k}-1 ; \mathrm{t}}^{\mathrm{A}}+\delta \mathrm{r}_{\mathrm{k}-1}+\xi_{\mathrm{k}}
$$

is the same as in Table 3 above and we refer to this table for further details. $\tau$ denotes the fraction of variance due to individual fixed-effects, $\rho(u, \mu)$ denotes correlation of the fixed-effects and conditional means. Stars refer to the level of significance: $* * *: \leq 0.01, * *: \leq 0.05, *: \leq 0.10$. 
Table A.6

Sub-sample analysis

\begin{tabular}{|c|c|c|c|c|}
\hline & $\begin{array}{l}\text { March } 11^{\text {th }} \\
\text { to } 15^{\text {th }} \\
\end{array}$ & $\begin{array}{c}\text { March } 18^{\text {th }} \\
\text { to } 21^{\text {st }} \\
\end{array}$ & $\begin{array}{l}\text { Trading mi- } \\
\text { nutes } 1 \text { to } 15\end{array}$ & $\begin{array}{c}\text { Trading mi- } \\
\text { nutes } 16 \text { to } 60\end{array}$ \\
\hline \multirow[t]{2}{*}{$\operatorname{LOOF}\left(\beta_{1}\right)$} & 0.201 & 0.344 & 0.402 & 0.350 \\
\hline & $* * *[3.43]$ & $* * *[4.10]$ & $* * *[3.72]$ & $* * *[3.22]$ \\
\hline \multirow[t]{2}{*}{ LOOF $\times \operatorname{size}\left(\beta_{2}\right)$} & -0.152 & -0.189 & -0.264 & -0.173 \\
\hline & $* * *[-4.22]$ & $* * *[-5.17]$ & $* * *[-4.89]$ & $* * *[-2.96]$ \\
\hline \multirow[t]{2}{*}{ Lagged oflow $(\gamma)$} & 0.041 & 0.036 & 0.026 & 0.041 \\
\hline & $* *[2.15]$ & $* *[2.21]$ & $* *[1.97]$ & $* *[2.49]$ \\
\hline \multirow[t]{2}{*}{ Lagged returns $(\delta)$} & 0.004 & 0.014 & 0.007 & 0.019 \\
\hline & {$[0.71]$} & [1.39] & {$[0.40]$} & $*[1.69]$ \\
\hline \multirow[t]{2}{*}{ Const. $(\alpha)$} & 0.043 & 0.074 & 0.068 & 0.051 \\
\hline & [1.56] & $* *[2.02]$ & $*[1.88]$ & {$[1.37]$} \\
\hline$R^{2}$ & 0.14 & 0.17 & 0.18 & 0.14 \\
\hline$\tau$ & 0.20 & 0.23 & 0.19 & 0.25 \\
\hline$\rho(u, \mu)$ & 0.25 & 0.30 & 0.26 & 0.29 \\
\hline Obs. & 5,293 & 4,495 & 4,682 & 5,006 \\
\hline
\end{tabular}

This table shows results for the analysis in Table 3 based on the regression

$$
\mathrm{x}_{\mathrm{k}}^{\mathrm{i}}=\alpha^{\mathrm{i}}+\beta_{1} \mathrm{x}_{[\mathrm{k}-1]}^{\mathrm{i}}+\beta_{2} \mathrm{x}_{[\mathrm{k}-1]}^{\mathrm{i}} \cdot \lambda_{[\mathrm{k}-1]}^{\mathrm{i}, \mathrm{C}}+\gamma \mathrm{x}_{\mathrm{k}-1 ; \mathrm{t}}^{\mathrm{A}}+\delta \mathrm{r}_{\mathrm{k}-1}+\xi_{\mathrm{k}}
$$

but we split the sample into different sub-samples. The left part of the table shows results for splitting the whole sample into subsamples of five and four days, respectively. The right part of the table shows results for splitting the sample into two subsamples of the first 15 minutes and last 45 minutes of the trading session, respectively. $\tau$ denotes the fraction of variance due to individual fixed-effects, $\rho(u, \mu)$ denotes correlation of the fixed-effects and conditional means. Stars refer to the level of significance: $* * *: \leq 0.01, * *: \leq 0.05, *: \leq 0.10$. 